\title{
LOS MAKÚ DEL NOROESTE AMAZÓNICO
}

\author{
Dany Mahecha Rubio \\ Carlos Eduardo Franky Calvo \\ Gabriel Cabrera Becerra
}

"Carecen de residencias fijas, hamacas y camoas. Si las lenguas macú son
realmente macro tucano, como lo ha sugerido Greenberg, los macú no son
un grupo totalmente ajeno entre sus vecinos culturalmente más avanza-
dos. Sin embargo, no contamos con estudio alguno de este grupo, de suerte
que no sabemos si pueden ser considerados como un vestigio de pueblos
primitivamente no-horticolas o de pueblos desarraigados que habtan
abandonado el cultivo. La selva tropical tiene un gran mimero de
ejemplos del último caso."

Irving Goldman (1968: 10) 
The connotations are examined of the name "maku", as used as a generic term for those peoples of the northwest Amazon with a nomadic tradition. A study of the historical, linguistic and ethnographic literature leads to the conclusion that "maku" is not the name of any particular ethnic group but is rather a term which both for the sedentary indigenous population and for those people who have studied groups known as "maku", has negative connotations. Furthermore, the indiscriminate use of this word over a period of time has led to confusion in classifying thesegroups; thesame term has been used for peoples who are linguistically and culturally different, obscuring the characteristics peculiar to each of them. Today these peoples live in specific contexts and maintain different relationships with the various sectors of national society and with other, neighbouring, indigenous societies, a situation which is modifying their ethnicity. The article concludes that it would best to continue to use the term Maku-puinave for the linguistic group as a whole while calling each of the peoples that make up this group by their own ethnic name.

Para el Noroeste-Amazónico se han propuesto dos modelos de adaptación y uso del espacio, uno basado en la "horticultura itinerante" y el otro en la caza y recolección en las áreas interfluviales (Lathrap 1968, Milton 1984, Reichel Dussan 1987); desde otra perspectiva, se han contrastado dos conjuntos sociales: los indigenas sedentarios riberefios y los cazadores nómadas "makú" (Correa 1983-1984 y 1987, Jackson 1983, Reid 1979, Silverwood-Cope 1990), que corresponden con los modelos anteriores.

El objeto de este artículo ${ }^{1}$ es presentar un marco general de referencia que contribuya a aclarar las implicaciones de emplear el término "makú",

1 Este artículo se basa en la Tesis de grado "Aportes a la etnografia de los n₹kak y su lengua - aspectos sobre fonologia segmental-", presentada al Departamento de Antropologia de la Universidad Nacional de Colombia para optar al título de Antropólogos. Las traducciones de las citas en francés son de Gabriel Schwarb, las de las citas en alemán de Roberto Berrio y las del inglés y el portugués de los autores.

2 También se escribe "macú", "macu" o "maku", pero sólo utilizamos "makú", siguiendo la transcripción de Koch-Grünberg (1906) y de Rivet y Tastevin (1920), porque las diferencias son de grafia y no corresponden con ningún nivel de análisis lingüistico. 
UBICACIÓN DE LOS GRUPOS DENOMINADOS"MAKU" POR AUTOR

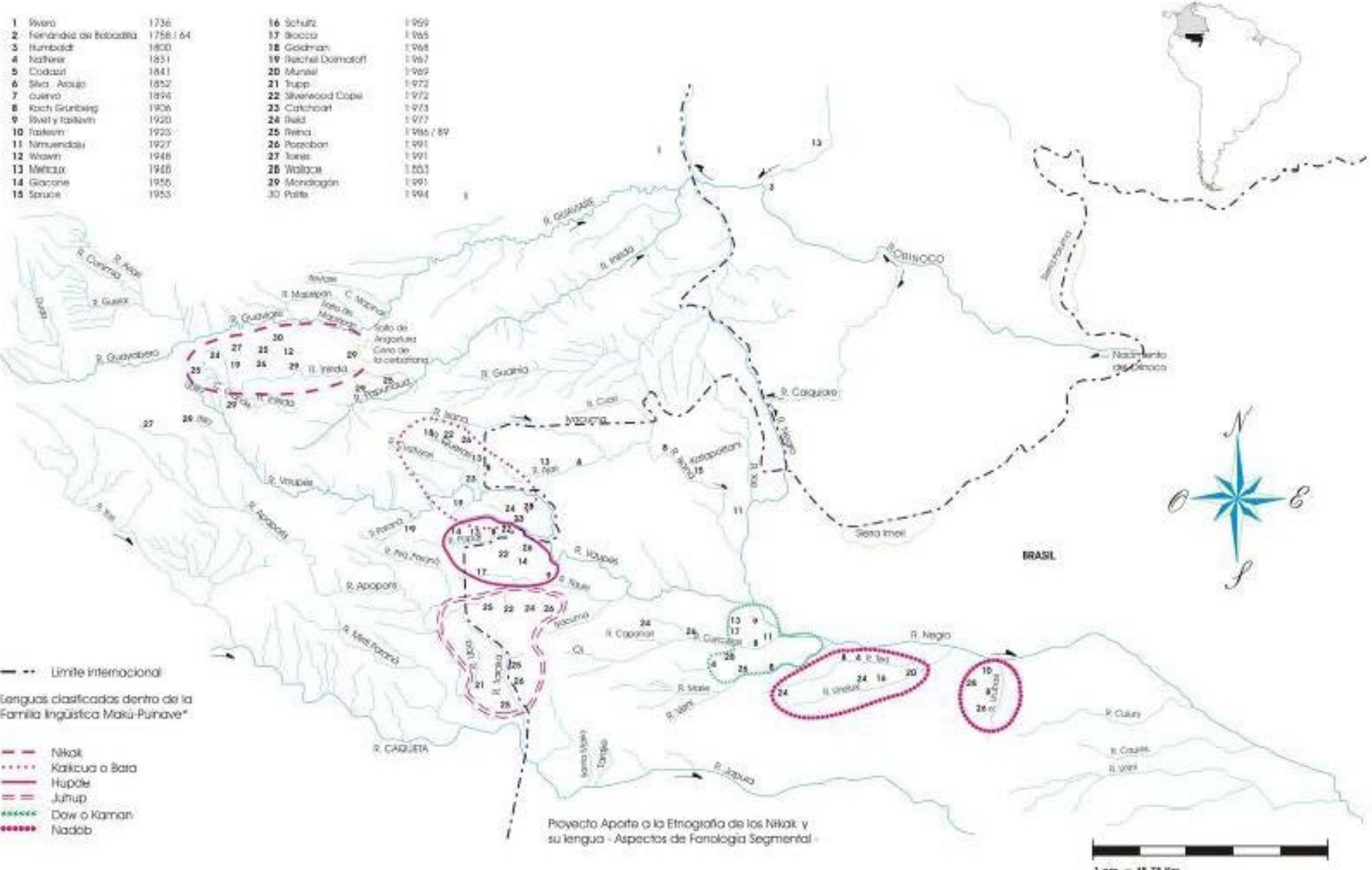


en los ámbitos lingüístico, etnográfico, económico y politico; al mismo tiempo plantea algunas hipótesis que explican porqué se ha utilizado para designar a un conjunto de pueblos de diferentes tradiciones socio-culturales y familias lingüfsticas.

Desde el siglo XVIII, el término "makú" ha sido usado en forma indiscriminada por viajeros, cronistas, funcionarios e investigadores para referirse a grupos de los cuales se capturaban personas para servir de esclavos y/o a grupos nómadas sin agricultura de las áreas interfluviales, algunos de los cuales pertenecen a la familia lingūistica Makú-puinave y mantienen una relación de subordinación frente a sus vecinos riberefios sedentarios que los tratan como sus "sirvientes" (Correa 1987, Friedemann y Arocha 1985, Goldman 1968, Jackson 1983, Koch-Grünberg 1906, Métraux 1948, Milton 1984, Ortiz,F. 1986, ReichelDussan 1987, Wallace 1992).

En el plano lingúistico, la familia Makú-puinave propuesta por Rivet y Tastevin en 1920 sigue vigente y se ha enriquecido con datos de investigaciones posteriores (Cabrera, Franky y Mahecha 1994, Cathcart 1979, Caudmont 1954, Girón 1995, Mahecha, Cabrera y Franky, en prensa, Mondragón 1991, Moore 1976, Ospina 1995, Pozzobon 1991, Reid 1979, Reina 1987 y 1990, Rivet, Kok y Tastevin 1925, Silverwood-Cope 1990, Tastevin 1923, Wirpsa y Mondragón 1988), que han permitido la identificación de siete pueblos y sus respectivos idiomas. Estos son: dow, hupdu, juhup, kakua, n+kak ${ }^{3}$, nadöb y puinave (véase mapa).

El kakua y el $n$;kak son idiomas mutuamente inteligibles (Cabrera et al. 1994, Mondragón 1991, Reina 1988 y 1990, Wirpsa y Mondragón 1988), al igual que el juhup y el hupdu(Pozzobon 1991). Sin embargo, estas dos posibles unidades no lo son entre sí, y ninguna de sus lenguas es inteligible con el puinave o el con el nadob, aunque el hupdu y juhup poseen gran similitud en fonos y estructura tonal con esta última (Reid 1979: 17). El dow tiene palabras y elementos gramaticales comunes con el juhup y con el hupd (Mattéi-Muller, Henley y Reid s.f:: 7).

Estos pueblos también han sido denominados o sus nombres escritos asi:

3 Escribimos " $n$ ₹kak" aunque la transcripción fonética es [ $n z k a k]$ y la fonológica es /d fkak/. Optamos por esta grafia en donde se mezcla lo fonético y lo fonológico porque es más cercana a nuestra lengua, pero conservando una vocal del idioma hablado por este pueblo indigena que no tiene ningún fono equivalente en el español. En la literatura existente tambièn aparece como "nukak" o "nukak-makù". Torres (1994) transcribe Nukák. 
- kakua como cacua(Cathcart 1973 y 1979, Tovar y Larrucea 1984), baramakú (Silverwood-Cope 1990, Salamand-Kuán 1996), kakwa o bara (Pozzobon 1991, Mattéi-Muller et al. s.f.); igualmente los llaman makú de Cubeo, makú de Guanano o makú de Desano (Cathcart 1973).

- hupdu como hupdu, hupdè, hupdr (Mattéi-Muller et al. s.f.), hüpde, übde, nehern (Giacone [1955] en Silverwood-Cope 1990, Reid 1979), hupdâ (Pozzobon 1991, Salamand-Kuán 1996), húbde, ubde-nehern (Ortiz, S.E. 1965), jupda(Moore 1976), hubde, hupda(Tovar y Larrucea 1984) o hupada (Pottier 1983); también se refieren a ellos como makú de Tucano (Tovar y Larrucea 1984).

- juhup como juhupde (Reina 1987), yohop (Silverwood-Cope 1990), yuhupdâ (Pozzobon 1991), yuhup, (Reid 1979, Salamand-Kuán 1996), yehúpde (Mattéi-Muller et al. s.f.) o yahup (Pottier 1983).

- nadőb como nade̋b, nadopa(Munzel 1969, Ortiz, S.E. 1965, Tastevin 1923), anodőub (Natterer [1831] en Munzel 1969), nadöbö (Tastevin 1923), nadobo (Biocca 1965), nadeb (Pozzobon 1991), nadębë, guarua-tapuyo, xiriwai (Mattéi-Muller et al. s.f.), guariba (Métraux 1948, Tastevin 1923), guaripa (Tovar y Larrucea 1984) o kaborí (Giacone [1955] en Silverwood-Cope 1990; Munzel 1969; Schultz 1959).

- dow como dao, kamaa (Mattéi-Muller et al. s.f.), dóu(Ortiz, S.E. 1965), dou (Tovar y Larrucea 1984), kama, kamá, kamã (Munzel 1969) o kaman (Pozzobon 1991).

Otra forma de mencionar a los pueblos llamados "makú" consiste en indicar el nombre del caño o río en el cual se hizo contacto o se tuvieron noticias de su presencia. Aqui debemos aclarar que en algunas referencias sólo se señala que determinado grupo es "makú" y no se especifica su ubicación geográfica, su autodenominación y/o su filiación lingúística, lo cual dificulta su identificación (véase Tabla 1).

De los pueblos denominados "makú", sólo los n₹kak, kakua, juhup y hupdu tienen sus territorios o parte de ellos en la actual república de Colombia. Los tres últimos viven en asentamientos semisedentarios e incluso conforman comunidades mixtas en las que conviven con miembros de otros grupos "makú" o con indigenas ribereños (véase Tabla 2). 
Ya investigadores como Munzel (1969), Biocca (1965), Triana (1985) y Reina (1987) han llamado la atención sobre la confusión etnográfica y linguística que se presenta alrededor de los pueblos que fueron y/o son denominados como "makú", la cual en parte se debe a que la mayoría de los autores se basan principalmente en la información presentada por Biocca (1965), Cathcart (1973, 1979), Giacone (1955 y 1969 en Silverwood-Cope 1990), Koch-Grunberg (1906), Munzel (1969), Reid (1979), Reina (1986), Rivet et al. (1925), Rivet y Tastevin (1920), Shultz (1959), SilverwoodCope (1990)4 y Tastevin (1923).

Silverwood-Cope y Reid elaboraron monografias etnográficas sobre los kakua y los hupdu respectivamente; a su vez Reina realizó estudios lingüisticos entre los juhup. A excepción de estos tres autores ${ }^{5}$, buena parte de la información publicada fue suministrada por indigenas ribereños, los cuales tienen una mirada peyorativa sobre los denominados "makú", que ha influido notoriamente en una descripción homogénea de los últimos. Refiriéndose a la imagen de los "makú" que se ha elaborado y difundido en distintas fuentes Munzel afirma que:

Debemos considerar también la posibilidad de que haya sido transformada por la interferencia de preconceptos en las informaciones sobre los makú, poco contactados directamente por etnógrafos. Sin poner en duda el carácter más arcaico de la cultura makú en comparación con la de sus vecinos, debemos observar el aspecto un tanto estereotipado de las descripciones y la extraña coincidencia con una imagen europea de salvajes bravos y feos (1969: 144).

Reina comparte esta opinión: "todos los grupos mencionados tienen denominaciones diferentes al término [makú]... En su mayoría las noticias de los makú, sus costumbres, formas de vida, etc, son referidas por terceros, a través de los indigenas TUKANO RIBEREÑOS" $(1987 ; 6)$.

Por lo tanto, sin pretender alcanzar la profundidad de una investigación etnohistórica, intentaremos delinear el contexto temporal y socio-espacial en el cual ha sido empleado el término "makú" y como se ha ido transformando en un apelativo genérico que actualmente define a un conjunto sociocultural y recalca la afinidad linguistica de las lenguas pertenecientes a la familia Makú-puinave.

4 La monografia de este autor, escrita en 1972, fue publicada en 1990.

5 Tenemos referencias de otros trabajos etnográficos y lingüisticos realizados en el Brasil, entre estos el de Jorge Pozzobon, "Parenté et demographie chez les indiens Maku." Thése de doctorat, Université de Paris VII, 1991; y el de Helen Weir, "A negação e outros topicos da gramatica Nadebb." $\mathrm{PhD}$ dissertation, Universidad de Campinas, Brasil; 1984. 
En algunos de los documentos de los siglos XVII, XVIII y XIX se emplean las palabras "maco" o "macas" y no "makú" propiamente, pero los contextos en que se usan nos permiten plantear que se trata de derivaciones del mismo término. Es así como, a mediados del siglo XIX, Wallace señala la existencia de grupos de "vida errante" en los bosques y sierras de la zona de los ríos Marié, Curicuriarí y Urubaxí a los que llama "macás" (1992: 393). En los dos primeros ríos están ubicados actualmente los dow y en el río Urubaxí los nadöb. A su vez Useche señala que,

"La expresión maco es usada por las fuentes orinoquenses tanto para designar a aquellos indigenas sometidos a servidumbre, como a un grupo étnico específico. Con todo, este último sentido aparece más frecuentemente en los relatos de la segunda mitad del siglo XVIII. En la actualidad sobreviven alrededor de unos 60 indigenas en el territorio Federal Amazonas (Venezuela), quienes son visitados por los misioneros salesianos a cargo del Alto Orinoco (comunicación personal de su misionero padre M. Marcucci). Aunque en el presente trabajo no discutimos este tipo de problemas, tenemos la impresión que podria haber un nexo entre el nombre funcional - maco, esclavo-y el "etnónimo" con que las fuentes españolas se refieren al grupo" (1987: 164).

Compartimos con Useche la asociación del término "maco" con "esclavo", pero no que este término corresponda a un etnónimo, porque ningún grupo se autodenomina con esta palabra ${ }^{6}$. Aunque actualmente algunos pueblos indigenas emplean "makú" para identificarse frente a los "blancos" $y$ a otros indigenas que los llaman de esta manera, tal comoes el caso de los juhupen el río Apaporis, área en la que se emplean como sinónimos "makú" o "makuje".

Además las fuentes que Useche emplea se refieren a un área especifica, el alto Orinoco, y es probable que los "maco" que menciona sea un grupo conocido como hoti" ${ }^{7}$, ubicado entre los ríos Ventuari y Orinoco y que según

6 Munzel (1969) explica que un grupo del alto Uneiuxi se autodenomina con orgulto "makú", pero que lo hace para manifestar su menor aculturación y mayor independencia; además señala que algunos grupos emplean como autodenominación "kama" y otros "nadob", que ambas palabras significan "gente" y son usadas para referirse a los menos aculturados, también llamados "makú bravos", reproduciendo en otra escala el esquema de discriminación de que son objeto por ser considerados "makú".

7 "La autodenominación hoti se aplica a varios grupos indigenas que hasta el presente habian sido considerados como independientes entre sí; los chicanos o shikanas (a veces asimilados, erróneamente, a los orechicanos yabaranas de filiación caribe), y los yuanas o wanuwarus de la zona del Parucito-Asita... pudo establecerse que los chicanos, yuanas y waruwarus constituyen en realidad un solo grupo con idénticas caracteristicas culturales y lingüisticas ${ }^{n}$ (Coppens 1975: 65). Este autor no precisa la filiación lingüistica a la que hace referencia. 
algunas clasificaciones pertenece a la familia lingüística Piaroa ${ }^{8}$ (Ortiz, S.E. 1965, Tovar y Larrucea 1984); Sin embargo, Mattéi-Muller, Henley y Reid mencionan a unos "mako" en los ríos Marieta y Ventuari cuya autodenominación sería hwïro o wirō y plantean la posibilidad de que "algunos Mako habrian venido del norte, desde las cabeceras de los ríos Paraguaza y Cuao, es decir relativamente cerca del territorio hodr" (s.f.: 26).

Por otra parte, preferimos emplear el término "esclavo" asociado a pueblos denominados "makú", sólo en contextos históricos especificos que están relacionados con la llegada al alto Orinoco de los espafioles, holandeses, portugueses (comerciantes, misioneros, etc), las caucherias de fines de siglo XIX y principios del $\mathrm{XX}$ que afectaron el noroeste amazónico y, las caucherias de mitad de siglo XX que aprovecharon las rutas establecidas por los primeros caucheros.

Todos estos fenómenos históricos se caracterizaron por el empleo de mano de obra indigena en diversas labores y de manera forzada: servidumbre en poblados establecidos por los europeos, recolección de caucho e incluso como bien intercambiable por mercancias u otros objetos. También fueron "cazados" o capturados y transportados a otros lugares (Domínguez y Gómez 1994, Gómez, Lesmes y Rocha 1995, Koch-Grüberg 1906, Llanos y Pineda 1982, Pineda 1985, Useche 1987).

Sobre la semántica del término "makủ" Giacone escribió que "el nombre 'Makú' quiere decir 'esclavo' en Nheengatu" (Searing 1980: 110). Taylor lo propone como "una palabra de las lenguas arawak del río Negro que significa carente de habla", "ma" es un privativo y "ku" significa idioma (citado en

8 "El nombre de este dialecto de la familia Sáliva lo escriben los lingüistas de diferentes maneras; Rivet, Castellvi y Mason usan máku; Loukotka, mako y Wilbert, macó. Preferimos la forma máku para evitar confusiones con el makú de la familia Puinave, el mako, dialecto Kofán y la familia Máku, de una sola lengua, descubierta por Koch-Grünberg en el rio Auary" (Ortiz, S.E. 1965: 123). Civrieux (1992) los llama maku o makushi, que no deben confundirse con los makuxi, también llamados makushi o makuchi (Pottier 1983), pueblo de la familia lingüistica Caribe que vive al extremo norte de Brasil y en la república de Guyana. Recientemente, MattéiMuller, Henley y Reid, basados en aspectos comunes de las estrategias socioeconómicas y en comparaciones lexicales, exploran una posible proximidad entre los "hoti" y los pucblos denominados "makú" y proponen la siguiente relación genética, "proto-Makú/hodi: hodi - nukaklkakwa - hupdilyuhuplkamaa - nadëb" (s.f: 24); estos autores dudan sobre la pertenencia de los puinaves al conjunto socio-lingüistico en cuestión.

9 Puesto que, como lo plantea Pineda (1985), estos procesos se deben analizar teniendo en cuenta la existencia de otro tipo de relaciones interétnicas prehispánícas asociadas al trato de huèrfanos y prisioneros de guerra. 
Landaburu 1990). En achagua (lengua arawak) "ma" es un privativo y "ku" tio, es decir, "sin tíos" o "sin parientes" (Miguel Angel Meléndez, comunicación personal 1993) y que podriamos interpretar como personas pertenecientes a otros pueblos indigenas.

En curripaco (lengua arawak) el término mákunai “...se compone de la raíz común ako (palabra, voz) precedida del privativo "ma". Mákunai se traduce entonces como las "gentes sin palabra [habla]" (Joumet 1988:98). Este autor refiere que el término se interpreta de diferentes formas, una de ellas para designar a otros clanes curripaco considerados menores ${ }^{10}$. De otra parte, Codreau (1890) propone que los makú son "...los restos de un pueblo muy antiguo y original, reducidos a esclavos por tribus vencedoras Tarianas, Tucanos, Uananas y Banivas" (citado en Koch-Grünberg 1906: 878).

Loanterior nos permite plantear que la palabra "makú" designabaa un conjunto de grupos que no hablaban lenguas pertenecientes a la familia linguística Arawak (ni Tucano oriental), que posiblemente fueron vencidos militarmente o que por lo menos tuvieron confrontaciones con grupos de habla arawak, en las cuales algunos de sus miembros o grupos completos eran tomados como "prisioneros de guerra". Este hecho puede estar relacionado con la propuesta de Meléndez que referencia la palabra "makú" como "sin parientes", es decir se trataba de huérfanos, inicialmente capturados en las guerras".

La tradición oral de los curripaco señala que los makú del Vaupés, en el siglo XIX eran víctimas de sus represalias por diversas causas; asi mismo, que algunos clanes curripaco son descendientes de prisioneros de guerra provenientes del Vaupés (Journet 1988).

10 Según Journet, los curripaco emplean el término "mákunai" para referirse a: "1) un número indefinido de grupos, que se supone viven al sur del Vaupés y en su valle alto, a los cuales los curripaco atribuyen prácticas de brujeria, responsables de enfermedades que afectan a sus niños pequeños. A veces de manera descuidada, los curfipaco designan el conjunto de lo habitantes del Vaupés como mákunai, 2) grupos localizados en el alto valle del Inírida, desconocidos hasta este dia, 3) ciertos grupos de Guahibo nómadas, localizados aproximadamente al norte del Guaviare los cuales igualmente tienen reputación como practicantes de brujeria vengativa. 4) ciertos grupos Piaroa del Orinoco que son calificados como mákunai al igual que el conjunto de los "Waika" (o Yanomami) del alto Orinoco, y finalmente esos pequeños grupos familiares que se suponen viven en el aislamiento total, en la zona interfluvial que separa el rio Isana del Cuyari, en pleno territorio curripaco" (1988: 96-97).

11 "Estos prisioneros eran incorporados a los respectivos grupos domésticos de los guerreros vencedores y, eventualmente un buen porcentaje de aquellos adquiririan filiación total en el grupo captor a través de matrimonios interétnicos" (ArvelloJiménez et al. 1989: 158). Véase también Llanos y Pineda (1982) y Pineda (1985). 
Esta denominación genérica se extendió en el Noroeste Amazónico entre pueblos de distintas familias linguísticas que poseen sus propias denominaciones para los pueblos llamados "makú", la mayoría peyorativas (véase Tabla 3); fue empleada para referirse a aquellos grupos que no hablaban su lengua (o alguna emparentada) y fueron tomados como "servidumbre" o como "esclavos" con ocasión de la llegada de los comerciantes europeos.

Así se explica parcialmente porqué en distintos documentos aparecen referencias de distintos pueblos como "macos", "macas" o "makú", los cuales no están emparentados lingüísticamente, tienen tradiciones culturales disímiles y se ubican en el noroeste amazónico, en las actuales repúblicas de Brasil, Colombia y Venezuela. Entre ellos están los yanomami, makuna, hoti, kofán, achagua, guahibo y piaroa, además de los pertenecientes a la familia lingúistica Makú-puinave (véase Tabla 1). Eso sin contar aquellos que se extinguieron con la llegada de los españoles o que fueron asimilados por grupos arawak y tukano y de los cuales no se tiene mayor información.

\section{LOS HABITANTES MÁS ANTIGUOS DEL NOROESTE AMAZÓNICO...}

Los pueblos denominados "makú" han sido considerados como los más antiguos habitantes del noroeste amazónico (Koch-Grünberg 1906, Métraux 1948, Nimuendajú 1950), planteamiento apoyado en evidencias linguísticas, históricas y etnológicas. Según Métraux, "los makú del Río Negro son generalmente considerados los últimos representantes de unas gentes antiguas, que ocuparon vastas áreas de la cuenca amazónica antes que fueran exterminadas o asimiladas por los Caribe, Arawak y Tukano, quienes tenian una cultura más avanzada basada en la agricultura" (1948: 865). Por su parte Koch-Grünberg plantea las rutas de invasiones arawak y tukano así:

"Los nombres de los ríos de toda esta región, terminados en ri, muestran que al principio vinieron arawaks desde el norte y el noreste, seguramente del territorio entre el Orinoco y el río Negro y que marcharon al Sur hasta el Yapurá [río Caquetá, en Brasil]. Aqui hallaron una población nómade primitiva makú que en parte fue destruida y en parte esclavizada, mientras otros huyeron. Luego vinieron del Occidente y del Suroeste los Tukano, tribus fuertes y rudimentarias que penetraron en forma de cuña entre el CaiaryVaupés y el rio Negro, entre los arawak, que huyeron al Norte o al Sur o fueron asimilados como en el caso de los Hölöua y los Baniwa del Querary" (Pineda y Guhl 1945: 183). 
Nimuendajú (1950) confirma estas rutas de migración. Otra referencia ratifica la presencia de pueblos denominados "makú" sobre el Vaupés, antes de la llegada de los arawak:

"En la lengua de los Arara-tapuya y de los Kadáu-puritãna, el río Vaupés se llama Ukayali; en las de los Huhúdeni, se dice Ukávari (las tres son del grupo Arawak). Podria, tal vez, derivar de U(ni), agua rio, y Kawale (en Kadaúpuritãna) o Kawáeri (en hihúdeni), viento. Y entre tanto ninguno de los viejos de las varias tribus Arawak de los rios Içana y Aiari, que pudimos consultar, sabian indicar el significado del término Caiari o Ucaiarí. Como tampoco lo sabian los de las otras tribus que habitan el Vaupés. Todos estos designan el Vaupés por "Dya Poxsa", rio de los Makú(?). Esta designación podria inducir a pensar que los Makú (Puxsá) fueron los primeros habitantes de sus márgenes, y después, por presión de las invasiones Arawak y Tukano se internaron en los bosques adyacentes, desde los alrededores de San Gabriel hasta los raudales de Jandú y Carurú (en el río Vaupés)" (Bruzzi Alves da Silva 1962: 10).

Lathrap (1968) argumenta que las evidencias arqueológicas, sólidas pero fragmentadas, $y$ las evidencias lingáisticas indican que la cuenca del Amazonas nunca fue penetrada tempranamente por gentes cazadorasrecolectoras, sólo por agricultores; de acuerdo con esto, las tribus ribereñas fueron las primeras colonizadoras de las riberas inundables del Amazonas; posteriormente su población creció y se extendieron, emigrando en todas las direcciones desde un centro demográfico. También señala que los cazadores de las áreas interfluviales del norte y oeste amazónico fueron en otro tiempo gentes que ocuparon ambientes ribereños más favorables y que por presiones de subsecuentes migraciones a las áreas inundables del Amazonas tuvieron que abandonarlas.

Reid señala que esta hipótesis es poco satisfactoria, en tanto no aclare por qué las primeras migraciones ocurrieron entre el 9000 A.C. y el 2500 A.C. y, además, porque se plantea,

“...erróneamente que todos los miembros de las culturas desarrolladas en el bosque tropical practican agricultura en las zonas inundables, cuando de hecho son pocos los que lo hacen. Su afirmación a priori de que la subsistencia en ambientes ribereños es mejor que la subsistencia en el medio ambiente selvático es una pregunta abierta, mientras su caracterización de estos grupos del bosque como "los restos de sociedades agricultoras desarrolladas, forzadas a entrar en un medio ambiente impropio a los patrones de economia 
básica", representa una falta de familiaridad con las etnografias de estos grupos" (Reid 1979: 20).

La propuesta de Lathrap se contrapone a la opinión de los hupdiy de los bara sobre la adquisición de sus conocimientos horticolas, pues ellos dicen que son recientes y que antes no los tenian (Reid 1979, Silverwood-Cope 1990), Según Reid:

"Los hupdu dicen que ellos son originarios del este, río abajo, y fueron los primeros en entrar al área, viajando a pie a través del bosque. Dicen que en esos tiempos no tenian agricultura, y subsistian enteramente de la caza y recolección. Los hupdu trazan esta jornada ancestral desde el Amazonas pero los bara-makú sostienen que ellos vienen del Noreste, de la dirección del Orinoco, y que ellos no tenian agricultura hasta hace unos cien años atrás. Los indios ribereños nombran su punto de origen como "Manao", en las bocas del Rio Negro, y trazan su jornada ancestral subiendo el río por canoa. Tenían conocimientos de la agricultura y de las técnicas complejas empleadas en el procesamiento de yuca brava, y descubrieron a los makú viviendo en los bosques cuando arribaron a la región en el Vaupés... Las opiniones de los indios hasta hoy confirman la idea de que los makú fueron los primeros ocupantes del área y verdaderos cazadores-recolectores en otro tiempo..." (Reid 1979: 21).

Por su parte, los nłkak afirman haber tenido, varias generaciones atrás, huertos más amplios que los actuales y que desaparecieron por razones que aún desconocemos; además, explican que como fruto del contacto con la sociedad nacional murieron muchas personas de su pueblo y que por esto perdieron algunas semillas ${ }^{12}$.

Hoy en día están recuperando algunas de éstas a través de los misioneros $y$ de los colonos. En su lengua se encuentran palabras que permiten inferir el intercambio de conocimientos y especies cultivadas con otros pueblos,

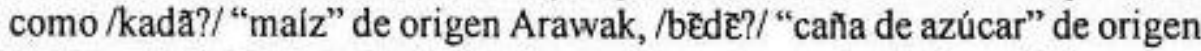
Cubeo; el chontaduro era llamado por los antepasados de los nikak como $1+\mathrm{r} \varepsilon /$, término similar al empleado por los actuales tukano (Antonio Guzmán, comunicación personal 1995).

12 Esto se explica por el ritual funerario que implica eliminar todas las pertenencias del difunto, incluidos sus sembrados; los nkak afirman que solo las palmas de chontaduro no se talan, aunque observamos que las plantas de achiote y los totumos tampoco se destruyen (Cabrera et al. 1994: 422-425). Vẻase también Franky, Mahecha y Cabrera 1994). 
Sobre su origen, los $n * k a k$ afirman que son gente del nivel inferior del mundo y que la primera gente salió por un hueco, que algunos ubican más abajo de Mitú (Cabrera et al. 1994:140-141). Este aspecto corrobora la cercanía cultural de los nkak y los kakua, aunque nos llaman la atención las discrepancias de criterios sobre la adquisición de prácticas agrícolas que tienen estos dos pueblos.

Por otro lado es de anotar que los resultados de investigaciones arqueológicas en la Amazonia colombiana, en el medio río Caquetá evidencian una ocupación antigua de grupos humanos cazadores recolectores, la cual fue fechada entre el 9000 y el 9300 A.P. (Cavelier et al. 1995: 29). Estos datos contrastan con los planteamientos de Lathrap (1968) e indican una colonización temprana del bosque húmedo tropical por parte de sociedades no agrícolas.

Sobre este tema, la hipótesis de Zucchi (1989) combina datos arqueológicos, lingúfsticos, históricos y de tradición oral y propone que entre los años 4200 y 3800 A.P. hubo una incursión de hablantes de proto-maipure (considerado como proto-arawak) en la cuenca del Río Negro, donde luego se dividieron en varios grupos. Uno de estos ocupó el río Isana y sus afluentes, la migración de estos sibs está documentada en la tradición oral de los piapoco, que señala al raudal del Hipaná como su sitio de emergencia, en el siguiente orden mitológico: "1. Unainuma, 2. Mauiliene (originalmente makú), 3. Molu dakenai (actualmente extintos), 4. Hohodene, 5. Adzanene, 6. el hermano menor de los Adzanene y 7. otros hermanos menores"(Wright en Zucchi 1989: 124). Según la autora.

"La historia oral de los Piapoco también refiere que una vez ocurrido el desprendimiento del sib primigenio en el Ayari, sus integrantes emprendieron un largo camino migratorio. Desde este río pasaron al Vaupés y lo remontaron hasta las cabeceras, y luego siguiendo un camino del Kuwai, pasaron al Alto Guaviare en donde permanecieron un tiempo. (Zucchi 1989: 124).

Posteriormente otros grupos migraron hacia el río Uva, en el Departamento del Meta y luego hasta el alto Orinoco. Nos llama la atención que se seffala una migración de grupos arawak que cruza una extensión importante de los territorios de pueblos denominados "makú" sin que se haga mayor mención sobre ellos, así como que los piapoco planteen que mitológicamente, algunos de sus sib fueran originalmente "makú", es decir que probablemente no hablaban su lengua y que posiblemente fueron asimilados como los Hohodene (Nimuendajú 1950). 
En conclusion, las evidencias sugieren que los ancestros de algunos pueblos "makú" fueron los primeros pobladores del área; establecer si eran cazadores-recolectores, la fecha de su llegada y, si desconocían o no la agricultura depende en gran parte de ampliar y confrontar las evidencias arqueológicas y lingúisticas y la tradición oral de estos grupos. Es de señalar que en la actualidad todos los pueblos denominados makú tienen prácticas agrícolas, aunque sólo los $\mathrm{n}+\mathrm{kak}^{13}$ mantienen sus patrones territoriales nomádicos, con una alta movilidad. Los hoti se encuentran en una situación similar (Reid, comunicación personal 1993).

\section{LOS "MAKÜ": SIRVIENTES Y ESCLAVOS}

Desde el siglo XVII se encuentran referencias sobre los "macos" término genérico que, como ya hemos mencionado, hacia referencia a los huérfanos que se intercambiaban con grupos caribe, que a su vez comerciaban con europeos. Es posible que dentro de estos "macos" se encontraran ancestros de los pueblos denominados actualmente como "makú", pero también se incluian otros grupos tratados como esclavos y servidumbre, que además no hablaban la lengua de sus captores y que posiblemente eran prisioneros de guerra.

En el alto Orinoco se menciona que poitos e itotos eran esclavos macos en el siglo XVII. A su vez grupos piaroas y guahibos eran considerados de igual forma. Sobre los achaguas el padre Rivero señala que:

“...apenas habia mestizo en los llanos, por pobre que fuese que no sirviera de macos Achaguas, y se consideraban más ricos los que tenían mayor número de ellos a su servicio... era tanto el desorden que no solamente se cautivaban estos macos para servirse de ellos, sino para venderlos a otros, y hacian sacos muy cuantiosos para proveer el reino como es notorio" (1956; 33).

Los comerciantes europeos promovieron la captura de macos y su comercio; al respecto se menciona que "los españoles demasiado dependientes del servicio personal del indigena, estimulan el tráfico de 'macos', (poitos, itotos, esclavos)" (ANC, Col. C. I,t 39, fl 906 en Useche 1987: 100). Estos" "no solo usaron los 'macos' en oficios domésticos en las sementeras y sobre todo como remeros en el Orinoco. También los usaron como

13 Cada grupo local $n^{2}+k a k$ construye aproximadamente 68,64 campamentos al año, con una ocupación por campamento de 5.31 dias y con una distancia recorrida en promedio de 6.9 kilómetros entre cada uno de ellos (Franky, Cabrera y Mahecha 1995). 
'moneda' para obtener mercaderías europeas del contrabando atlántico (Useche 1987: 100).

Al parecer la tradición del intercambio de huérfanos tiene raices prehispánicas, siendo los grupos caribe reconocidos por ello (Gumilla 1963, Rivero 1956). Y si se tiene en cuenta la referencia de Meléndez, sobre el significado del término "makú" como "sin pariente" o como gente que ha sido aislada de su grupo, se explica el empleo del término en ese sentido: bien porque fueron vencidos militarmente o porque, durante los siglos XVII y XVIII, fueron capturados por otros indigenas, con ocasión de las guerras que desataron los europeos en el área, para conseguir mano de obra entre los nativos.

A la postre esta situación llevó a que la tradición de emplear a los huérfanos como servidumbre o como objeto de intercambio en forma similar a lo que los cronistas denominan "rescate"14 , se convirtiera en una cadena de enfrentamientos entre distintos grupos, aquellos que pretendian capturar esclavos y quienes se resistian a ser esclavizados o sometidos en tanto que, "los comerciantes blancos incitaron a los diferentes grupos indigenas a hacer la guerra entre ellos con el propósito de obtener esclavos para traficar" (Hugh-Jones 1981: 33).

Consideramos que es en este contexto histórico donde el término "maco" adquiere la connotación de esclavo, y se acentúa con los periodos de mayor auge de las economías extractivas, como la explotación del caucho, cuando se reactivan fenómenos de "esclavización" de grupos indigenas por otros indigenas y, de estos últimos, por comerciantes colombianos y peruanos en el Vaupés y el Caquetá (véase Pineda 1985, HughJones 1981).

Herndon y Métraux, (citados en Munzel 1969), y Hugh-Jones (1981) coinciden en plantear que estos fenómenos históricos afectaron los patrones económicos y socio-políticos de algunos pueblos denominados "makú". "Herndon explica la vida nómada y guerrera de los makú como resultado de las cacerías de esclavos de que fueron victimas" (Munzel 1969: 143). Métraux procura explicar la diferencia en la cultura material entre los "makú

14 El rescate es "ia operación mediante la cual se canjeaba con los indigenas mercaderias europeas por esclavos y productos de la tierra. Fue la forma habitual no sangrienta (ya que es imposible hablar de pacifica) de comercio en la época" (Useche 1987: 42). 
bravos" y los "makús mansos" como la decadencia resultante del contacto de los segundos con los blancos, en tanto que los "makú bravos" han tenido menos contacto y conservan mayor número de objetos (Munzel 1969: 143).

También se plantea que uno de los efectos de las caucherías fue estimular "luchas entre las tribus para conseguir esclavos para traficar y, en particular transformó el rol tradicional de Makú que pasó de ser un ser inferior a ser un esclavo vendible que podía ser capturado" (Hugh-Jones 1981: 36). Koch-Grünberg describe a los "makú",

"Como odiados por sus vecinos que son tribus sedentarias más avanzadas, son seguidos como animales, deben trabajarles como esclavos en sus casas y en el campo, son vendibles a los europeos y blancos, hacen trueques con ellos, los intercambian por armas y productos a los comerciantes blancos" (1906: 877).

Este autor recorrió la región en pleno auge de las caucherías y recopiló parte de los vocabularios que le permitieron a Rivet y Tastevin (1920) plantear la existencia de la familia lingústica Makú-puinave. Goldman (1968) seffala que los denominados "makú" han sido sirvientes o "esclavos" de la mayoria de los pueblos de las familias linguísticas tukano y arawak de la región. Reichel-Dolmatoff señala al respecto, "todas las tribus vecinas consideran a los Makú como verdaderos esclavos que les 'deben servicios' y los Makú parece que aceptan este papel... Sin embargo, sólo los Desana, Tukano y Tariana 'tienen makú', es decir, consideran tener el derecho de usar sus servicios" (1986: 44).

No obstante, los dos últimos autores no observaron "esclavos makú" como tal en los grupos mencionados para la época en que realizaron su trabajo de campo y ellos mismos ponen en tela de juicio el que los grupos denominados "makú" sean realmente sirvientes de los otros grupos. Al respecto seffala Goldman:

"Pareceria que, lejos de ser esclavos, había una relación simbiótica entre estas personas bastante toscas y no agricolas, que no tenian aldeas o casas permanentes de su propiedad, y los cubeo. Estos no dan importancia a las ventajas económicas que significaban para ellos los borówa ["makú"], excepto que ayudaban en todos los quehaceres. En cualquier caso, ningún cubeo fue relevado de cualquiera de sus tareas normales debido a la presencia de los borówa" (1968: 139). 
"Mi propia información sobre los "esclavos" makú es sólo de oidas, ya que hasta donde pude saber, todos los sibs cubeo de Cuduiari habian renunciado al sometimiento de los borówa" (1968: 140).

Reichel-Dolmatoff hace la siguiente acotación sobre los grupos denominados "makú": "Algunos sin embargo son del todo independientes y viven aún apartados en las selvas, siendo considerados como 'malos' y antropófagos, pero la mayoría existe en simbiosis cultural con las tribus sedentarias" (1986; 44).

Silverwood-Cope (1990) y Reid (1979) sefralan que los bara y los hupdu fueron reclutados por indigenas ribereños, aprovechando los servicios tradicionales de los "makú", para trabajar para los caucheros a principio y mitad de este siglo, es decir durante el auge de este tipo de economia extractiva ${ }^{15}$. No obstante, estos mismos autores y Jackson (1983) seffalan que en la actualidad no hay evidencias suficientes para hablar de una servidumbre forzada o voluntaria de los grupos denominados "makú" frente agrupos ribereños, aunque se presenta una relación de intercambio de bienes y servicios entre ambas partes.

Las caracteristicas de los intercambios que se dan entre un grupo riberefio sedentario y un grupo denominado "makú" no son propiamente las de una servidumbre obligada, pues los segundos no hacen nada que no quieran y en cualquier momento se pueden marchar del asentamiento en donde laboran. Además intercambian objetos manufacturados como canastos, una sustancia alucinógena en forma de polvo, curare, carne moqueada, frutos silvestres, resinas de árbol y otros objetos de carácter ritual como plumas, dientes de monos, pecaries y jaguares por productos de los huertos como yuca, aji, coca, tabaco y productos occidentales como machetes, chaquiras y ropa (Silverwood-Cope 1990, Reid 1979).

Entre las labores que prestan los hombres "makú" a sus vecinos tucano están los trabajos en el huerto, mantener el fuego de la casa encendido toda la noche y colaborarle al "patrón" tukano en diversos oficios domésticos; las mujeres ayudan en la elaboración del cazabe, acarreo de agua y en partir lefia, pero las mujeres tukano no dejan de hacerlo por la presencia de las mujeres "makú" (Jackson 1983).

15 Según Reid (1979) los hupdu se internaron en el centro del área interfluvial de su territorio para protegerse de los abusos de los caucheros, a principios de este siglo, y no fueron afectados mayormente con el repunte de la bonanza cauchera en los años cuarenta del presente siglo. 
$\mathrm{Al}$ respecto Buchillet (s.f.) anota que la relación entre estos dos tipos de sociedades se ha considerado como de patrón-esclavo, pero dada la independencia de los makú y su nomadismo se debe interpretar en términos de trueque económico: trabajo, productos del bosque y canastos por' comida y productos adquiridos por los tukano a los blancos. Este intercambio parece desigual para los makú, pero ellos aceptan la ganancia temporal que obtienen y podría pensarse que obtienen beneficios en otros dos planos: el miedo que les pueden inspirar a los tukano y el aprendizaje de saberes técnicos, cosmológicos o terapéuticos.

No obstante, en la mitología tukano (Jackson 1983) y en la tradición de los cubeo (Goldman 1968) los pueblos denominados "makú" aparecen como los últimos en llegar o descender de la anaconda celeste en el mito de la creación, y además como a quienes no se les dio agricultura, sólo "la cerbatana y un canasto" (Reichel-Dolmatoff 1986: 53), elementos con los que se identifican como especialistas dentro de la compleja red de intercambios de productos entre distintos grupos en el Vaupés (Searing 1980). Goldman también señala:

“...Un subsib de los bahúkiwa que también es conocido por la connotación derogatoria de mánapwänwa (gente que se arrastra) o mánawa. De acuerdo a las tradiciones, no fueron cubeo, sino un grupo nómada, quizás macú, que había llegado al Cuduiari por tierra y cuyo sitio de emergencia fue el Querari mirí, pequeño tributario del Cuduiari. Los bahúkiwa los adoptaron y les dieron nombres personales de su propia genealogia del sib" (1968:132).

"Existe una tradición de origen que dice que los borówa fueron los últimos en emerger de Uaracapuri y que por esta razón se les mantuvo como sirvientes de los otros" (1968: 139).

El hecho de ser señalados como "gente que se arrastra" está relacionado con que los pueblos denominados "makú" siempre han sido descritos desplazándose a pie y sin canoas (Koch-Grünberg 1906, Jackson 1983).

Hugh-Jones (1979) sefiala que entre los barasana los sibs con el status más bajo en el orden jerárquico son señalados como "los encendedores de cigarros" (asi mismo son considerados por los curripaco, Juan Manuel Castellanos, comunicación personal 1994), en forma análoga al rol de 
sirviente de los pueblos denominados "makú", que otorgan otros grupos tukano del Vaupés ${ }^{16}$.

Munzel (1969) menciona que en el sistema jerárquico que abarca las tribus del medio y alto río Negro, los pueblos denominados "makú" ocupan la posición inferior. Por su parte Jackson (1983) plantea que el bajo status de los pueblos denominados "makú" es real y estájustificado mitológicamente al ser asociados con la última gente que llegó en la canoa de la anaconda.

Como ya mencionamos, los ancestros de los pueblos denominados "makú" parecen ser los primeros pobladores del área y podemos considerar que la confrontación de la mitologia de los grupos tukano y arawak y la tradición oral de estos pueblos tiene que ver con la justificación de hechos históricos, tales como la asimilación de grupos "vencidos militarmente" en las distintas "invasiones" caribe, arawak y tukano. Se conocen diversos ejemplos de esta situación como el de los kaua o kawa-tapuyo - población mayor del Aiary - que emigraron del Querary, donde fueron invadidos por un grupo Tukano y adoptaron su lengua y costumbres; alli tuvieron relaciones con los Siusi Arawak y en 1903 sólo la población anciana hablaba el Kobeua (tukano) ya que los jóvenes hablaban arawak (Koch-Grünberg en Pineda y Guhl 1945: 178),

Otros grupos que no fueron asimilados y que afrontaron las épocas de auge de comerciantes europeos y caucheros se refugiaron en el bosque $o$ buscaron protección con grupos aislados riberefios y lograron mantener una relativa independencia, como los $\mathrm{n}+\mathrm{kak}$ (Cabrera et al. 1994, Mondragón 1991), los hupdu (Reid 1979) o los hurumi (Matallana y Schackt, 1991), estos últimos ubicados entre el río Yari y el río Apaporis. El hecho de ser grupos hostiles o renuentes a hacer contacto con los "blancos" u otros indigenas riberefios ha sido parte de la caracterización estereotipada de los pueblos denominados "makú".

Otro aspecto que se menciona para caracterizar la relación de subordinación de los makú, es que sus mujeres son objeto sexual de sus vecinos, indígenas ribereños (Koch-Grünberg 1906, Métraux 1948, Biocca 1965). Sin embargo, esta situación se encuentra asociada a descripciones de terceros que consideran a estos pueblos como sus sirvientes y aunque se

16 Hugh-Jones (1979) señala que los barasana no tenian relaciones con pueblos denominados "makú", por lo menos na durante la realización de su trabajo de campo. 
presenten relaciones sexuales se deben considerar los contextos históricos en que estos servicios eran impuestos a las mujeres "makủ".

Cabe anotar que las relaciones matrimoniales entre mujeres "makú" y hombres tukano son escasas y aún más extrañas las de hombres "makú" y mujeres tukano. Lo cual tiene que ver con el hecho de que la mayoria de los pueblos llamados "makú" son endógamos y no tienen relaciones de intercambio matrimonial con los grupos tucano, en parte porque estos últimos consideran inferiores a los primeros (Silverwood-Cope 1990). Al respecto sefiala Gómez: "que la diversidad lingúistica deba compaginarse con el sistema matrimonial es una convicción tan profundamente anclada en la conciencia de los Tucano que, según su punto de vista, las sociedades que la ignoran son incestuosas" (1986: 22); una situación similar se reporta en las relaciones entre los mákunai y los curripaco (Journet 1988).

Así mismo, las relaciones interétnicas con sus vecinos ribereños se establecen en la lengua de estos últimos, recalcando en otra forma su status subordinado. Sin embargo, se encuentran referencias que permiten plantear que las relaciones entre los pueblos denominados "makú" y los pertenecientes a las familias lingüisticas arawak y tukano no fueron siempre de subordinación, incluso Jackson (1983) plantea que los tukano reconocen que grupos "makú" fueron sus aliados militares en épocas antiguas. También se conoce una alianza, en 1767, entre varios grupos incluidos los "makú", para defenderse de los espafioles, sefialando que:

"La ocupación de parte de su territorio y la vida de pueblo a la cual fueron sometidos llegó a su fin mediante una rebelión Ye'cuana para la cual reclutaron aliados en tribus vecinas: los Macu, los Yabarana y los Wikiari de los Rios Ventuari y Merevari por lo que los españoles se vieron forzados a retirarse hacia Angostura" (Arvello-Jiménez 1992: 14).

Otros documentos permiten inferir que pueblos denominados "maku" tenian un rol especifico asociado al intercambio de ciertos productos en el área, aprovechando su característica de nómadas que se desplazaban en las áreas interfluviales. El siguiente texto confirma lo expuesto:

"Los macos contactados por Bobadilla eran una "capitania" que al parecer entraba en relación con los españoles por primera vez, puesto que con los 
holandeses ya habian trabado contacto en calidad de esclavos de los comerciantes caribes del Caura. Habian acudido al Unitamoni y al Padamo a "hacer feria" con los maquiritares. La fuente los describe como de pequeña estatura, habitantes de sabana y destacados en la fabricación de curare, cerbatanas y canastos de bejuco (Bobadilla 1908, 324). Al irrumpir los españoles en la aldea maquiritare, encontraron "gran música de trompas y oboes que lo tañian los indios macos que habian venido a hacer feria" (Bobadilla. 1964, 391) (Useche 1987; 164).

A su vez se menciona que los makú:

“...Localizados en el Auari central, afluente de izquierda del alto Uraricuera. Son nómades y buenos comerciantes. Nada tienen qué ver con las numerosas hordas de las regiones del Río Negro, ni con los Maku de la ribera derecha del bajo Ventuari y del Orinoco Central" (Koch-Grünberg en Pineda y Guhl 1945: 181).

También se ha considerado que los "makú" son especialistas en fabricar cerbatanas, veneno curare y canastos. Todos los grupos canjean con ellos el veneno curare que consideran como el mejor para la caceria (Bruzzi da Silva 1962, Searing 1980, Hugh-Jones 1981).

Según Reichel-Dolmatoff (1986: 44). “... los Desana designan a los Makú como nixi-maxsa, gente que pide, dependientes, y los Makú se llaman a sí mismos nixisóri-maxsa, proveedores, para recalcar su status". Sin embargo, es importante llamar la atención sobre el término "proveedores"; si la traducción de este autor es precisa, no "recalca" su status bajo, por el contrario, permite entrever una forma de relación basada en el intercambio de bienes y servicios.

Se señala además otro tipo de relaciones entre pueblos denominados "makú" y pueblos ribereños como el intercambio de conocimientos chamanisticos, pues son temidos y respetados por sus conocimientos en este campo (Koch-Grünberg 1906, Goldman 1968, Journet 1988, SilverwoodCope 1990). Cabe anotar que esta relación de "simbiosis" o de intercambio de productos y conocimientos se presenta entre otros grupos nómadas y sedentarios, como entre los achagua y los chiricoa-guahibo (Morey y Morey 1975, Ortiz, F. 1986) y entre los ye'kuana y los guaharibo (Arvello-Jiménez 1992).

Este tipo de intercambios entre distintos grupos del área, bien documentado por Morey y Morey (1975) para los llanos y Arvello-Jiménez et al. 
(1989) para el área del Orinoco ${ }^{17}$, probablemente se vio afectado con ocasión de la llegada de los europeos y criollos quienes alteraron profundamente las relaciones socio-politicas, económicas (Hugh-Jones 1981) y territoriales de estos grupos causando enfrentamientos entre distintos grupos, disminución considerable de la población, asi como movimientos poblacionales de desplazamiento buscando huir y refugiarse en áreas alejadas de los "blancos". Tambien se dieron cambios en los patrones de subsistencia como la sedentarización de grupos indigenas alrededor de poblados, alterando las relaciones entre los grupos del área interfluvial y los grupos riberefios, como lo sefialan Arvello-Jiménez et al::

"De allí que las poblaciones de la parte ribereña y de la interfluvial que hasta el siglo XVIII estaban conectadas por un flujo horizontal de bienes y servicios desde entonces estén unidas por un flujo vertical que tiene su origen en el valor diferencial con que desde entonces se tasan los productos indigenas frente a los productos de manufactura europea y/o criolla" (1989: 163).

El status de los pueblos denominados "makú" - quienes en otro tiempo se ocupaban del intercambio de productos entre distintos grupos-se fue transformando con la estratificación social producida por la subordinación económica, debido a que ellos dependian de los grupos riberef̃os para acceder a los objetos que traían los europeos: Se interrumpió así el flujo de información y bienes tradicionales entre ambas parte, y fueron tomados como sirvientes y esclavos, en contextos históricos específicos como ya mencionamos. Posteriormente con la decadencia de las caucherias algunos grupos recuperaron su independencia y se volvieron a articular como sociedades en procesos de reestructuración étnica.

Desde hace varios años, grupos juhup, ubicados en ambas márgenes del rio Apaporis en la zona fronteriza con el Brasil, viven en asentamientos semisedentarios independientes de los grupos ribereños con los que siguen teniendo relaciones de intercambio (tukano en Pari Cachoeíra, y tanimuka, letuama y makuna, en los rios Caquetá y Apaporis); realizan además intercambios con los colonos, colombianos y brasileros, $y$ otros indigenas de la zona.

17 "Dada la variedad de microambientes existentes, los guahibo y sus vecinos (principalmente los achagua) crearon mecanismos de cooperación y reciprocidad que permitian aprovechar conjuntamente esos microambientes con otros grupos culturalmente diferentes. Asi se superaba el problema de la competencia por recursos escasos y aún las limitaciones politicas" (Arvello-Jiménez et al. 1989: 160). 
Por su parte los nkak no reconocen el apelativo de "makú", ni de indios $o$ indigenas $y$ han permanecido aislados de sus vecinos ribereños, guayabero, guahibo y sikuani al norte, y puinave al sureste. Hasta hace siete años tenian confrontaciones esporádicas con los colonos y aunque se conocen parcialmente las razones de su aislamiento y su pasado en general, actualmente no prestan ningún tipo de servicio a sus vecinos indigenas ribereños y sólo

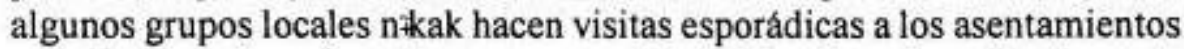
guayabero y sikuani, en la margen sur del rio Guaviare. Sus relaciones de intercambio se dan principalmente con los misioneros de Nuevas Tribus y con los colonos.

Luego de más de una década de contactos permanentes con la sociedad nacional brasileña, los dow se están recuperando de la baja demográfica que causaron estos contactos, aunque viven en asentamientos sedentarios y presentan altos índices de alcoholismo y de prostitución (Reid, comunicación personal, 1994). Por el momento, no tenemos mayor información sobre la relación actual entre los hoti, los nadőb y sus respectivos vecinos.

Si bien actualmente no se presentan relaciones de servidumbre, no se puede negar que aún se mantiene la marginación por parte de los indigenas ribereños con quienes se relacionan y también de los "blancos" con quienes comparten sus territorios. Y tanto los juhup como los kakua en el Vaupés son discriminados por las organizaciones indigenas regionales ${ }^{18}$. De esta forma afrontan una doble discriminación, la de los "blancos" y la de los propios indígenas ribereños. Silverwood-Cope sef̃ala al respecto:

"En todos sus contactos con los hombres blancos, los Makú han sido abordados en el papel que les han asignado los indios Tukano ribereños. No solamente los caucheros, también los misioneros católicos y protestantes y todos los etnógrafos, cuyos trabajos están publicados, todos de maneras diferentes, adoptaron actitudes de los indios ribereños en su trabajo con los Makú" (1990: 27).

A lo anterior se suma el hecho de que los distintos pueblos "makú" han tenido procesos históricos disímiles (incluso entre grupos que hablan la misma lengua) y la ubicación geográfica ha jugado un papel determinante en ello.

18 Aunque la Organización Nacional Indigena de Colombia (ONIC) ha mostrado un especial interés por defender los derechos de los ñkak. 
En primera instancia, podemos afirmar que los grados de acercamientos con misioneros (católicos o protestantes), comerciantes (portugueses, holandeses, españoles, etc), colonos, narcotraficantes, mineros, instituciones estatales y privadas, investigadores o grupos armados no han tenido la misma intensidad y cada uno se ha relacionado con sectores específicos de la sociedad nacional venezolana, brasileña y colombiana. En segundo lugar, se relacionan con distintos pueblos ribereños (makuna, desana, barasano, cubeo y otros) y ello desde luego altera sus patrones tradicionales culturales y genera sincretismos y conflictos particulares. En tercera instancia, actualmente los pueblos denominados "makú" tienen problemas de orden socio-politico y cultural especificos. Por ejemplo, algunos grupos locales n contacto permanente con colonos y otros tienen mayor interacción con los misioneros de la Asociación Nuevas Tribus en el sector oriental del territorio. Mientras tanto, los juhup del río Apaporis tienen serios problemas con el desarrollo de la mineria en el río Traira, en zona fronteriza con el Brasil, al igual que los dow y los hupdu que afrontan la presencia de la companías mineras Paranapanema (Meira 1991) y Gold Amazon respectivamente.

\section{CONSIDERACIONES FINALES}

Este breve análisis del término "makú" evidencia lo siguiente:

- Es una denominación externa y no corresponde a ningún etnónimo, por el contrario es un concepto genérico que contiene un matiz peyorativo y de subvaloración cultural.

- En la literatura etnográfica contemporánea se sigue hablando de los "makú" y de sus relaciones con otros pueblos indigenas o con la sociedad nacional; este tratamiento indiscriminado contribuye al desconocimiento sobre estos pueblos.

- En términos político-administrativos, la falta de claridad existente tiene implicaciones para estos pueblos cuando se diseñan y ejecutan planes de inversión y/o programas de cualquier índole (salud, educación, nutrición, etc) - especificamente para el caso colombiano, en el momento en que se propone la creación o ampliación de resguardos y se distribuyen los recursos de transferencias que les corresponden, así como en el proceso de reordenamiento territorial señalado en la 
Constitución de 1991 - ya que generalmente son olvidados o no se tienen en cuenta sus especificidades socio-culturales ${ }^{19}$.

Por lo tanto proponemos que el término "makú" no se emplee en forma aislada en los cfrculos académicos, administrativos o políticos para denominar a pueblos indigenas o a un conjunto de lenguas, hasta tanto no se profundice en el estudio de ellas y se precise su independencia o unidad. Mientras esto se logra, lo más conveniente es seguir llamando a esta familia lingúistica Makú-puinave y utilizar los etnónimos propios para identificar a cada uno de los pueblos que la conforman.

En este sentido, la declaración del encuentro continental de los pueblos indigenas proclama el respeto por las denominaciones propias (Mires 1992: 226) y la Constitución de Colombia protege la diversidad étnica y cultural del país. Además, el uso de los etnónimos propios podrá evitar las confusiones que se dan al momento de presentar y describir las familias lingüisticas y si cada referencia aclara de qué pueblo se trata, se fomentará el uso de las autodenominaciones y se tendrá un mejor panorama de las relaciones interétnicas, actualizando la información existente.

Finalmente, recordamos que dentro de la familia lingũistica Makúpuinave se han identificado hasta el momento siete pueblos con sus respectivos idiomas, estos son: dow, hupde juhup, kakua, $n+k a k$, nadob y puinave.

19 Un ejemplo de las implicaciones politicas y administrativas de la falta de claridad existente se refleja en el Programa de Apoyo y Fortalecimiento Etnico de los Pueblos Indigenas de Colombia (1995-1998), formulado por la División de Asuntos Indigenas del Ministerio del Interior, en donde se relaciona de manera incompleta y confusa a los pueblos denominados "makú". En este programa se habla de los "macu-nukak"; por la ubicación geográfica podemos inferir que se distingue a los n*kak de los otros "makú", pues se marcan áreas en donde se encuentran grupos juhup y hupda A su vez se mencionan unos bara y no es claro si se refiere a los kakua o al pueblo que pertenece a la familia lingüistica tukano oriental. 


\begin{tabular}{|c|c|c|c|}
\hline \multicolumn{4}{|c|}{ TABLA 1} \\
\hline Autor (es) & $\begin{array}{l}\text { Localización } \\
\text { del(os) Grupo(s) }\end{array}$ & Año & $\begin{array}{c}\text { Filiación } \\
\text { Lingüistica y/o } \\
\text { Denominación }\end{array}$ \\
\hline Rivero (1956) & $\begin{array}{l}\text { Llanos de Casanare y los } \\
\text { rios Orinoco y Meta. }\end{array}$ & 1736 & $\begin{array}{l}\text { Refiriéndose a los } \\
\text { achaguas. }\end{array}$ \\
\hline $\begin{array}{l}\text { Fernández de Bobadilla } \\
\text { (citado en Useche } \\
\text { 1987) }\end{array}$ & $\begin{array}{l}\text { Entre los curso altos del } \\
\text { Unitamoni (actual } \\
\text { Vatamú?) y el Ocamo, } \\
\text { aunque también se } \\
\text { reportan como habitando } \\
\text { cerca de las cabeceras del } \\
\text { Caura. }\end{array}$ & $\begin{array}{l}1758 \\
1764\end{array}$ & . \\
\hline $\begin{array}{l}\text { Humboldt (citado en } \\
\text { Useche 1987) }\end{array}$ & $\begin{array}{l}\text { En las orillas del rio } \\
\text { Ventuari, en el pueblo de } \\
\text { Santa Bárbara, fundado en } \\
\text { la orilla izquierda del } \\
\text { Orinoco, un poco al oeste } \\
\text { de la desembocadura del } \\
\text { Ventuari. }\end{array}$ & 1800 & \\
\hline $\begin{array}{l}\text { Natterer (citado en } \\
\text { Useche 1987) }\end{array}$ & $\begin{array}{l}\text { Rio lja, afluente del } \\
\text { Marié. } \\
\text { Rio Teia }\end{array}$ & .1831 & $\begin{array}{l}\text { Makú } \\
\text { Anodðub-makú. }\end{array}$ \\
\hline $\begin{array}{l}\text { Codazzi, A. (citado en } \\
\text { Iribertegui 1987) }\end{array}$ & $\begin{array}{l}\text { En los rios Pargueni y } \\
\text { Anaveni. }\end{array}$ & 1841 & macás \\
\hline $\begin{array}{l}\text { Silva Araujo (citado en } \\
\text { Llanos y Pineda 1982) }\end{array}$ & $\begin{array}{l}\text { En los poblados de Maripi, } \\
\text { Castanheria, Curiana e } \\
\text { Iparana. }\end{array}$ & 1852 & \\
\hline $\begin{array}{l}\text { Alfred R Wallace } \\
(1992)\end{array}$ & $\begin{array}{l}\text { Rios Mariè, Curicuriari y } \\
\text { Urubaxi }\end{array}$ & 1853 & \\
\hline $\begin{array}{l}\text { Martius (citado en } \\
\text { Koch-Grünberg 1906) }\end{array}$ & No precisa sitio & 1867 & \\
\hline $\begin{array}{l}\text { Cordeau (citado en } \\
\text { Koch-Grünberg 1906) }\end{array}$ & No precisa sitio & 1890 & \\
\hline $\begin{array}{l}\text { Cuervo (citado en } \\
\text { Llanos y Pineda 1982). }\end{array}$ & Yari & 1894 & \\
\hline
\end{tabular}




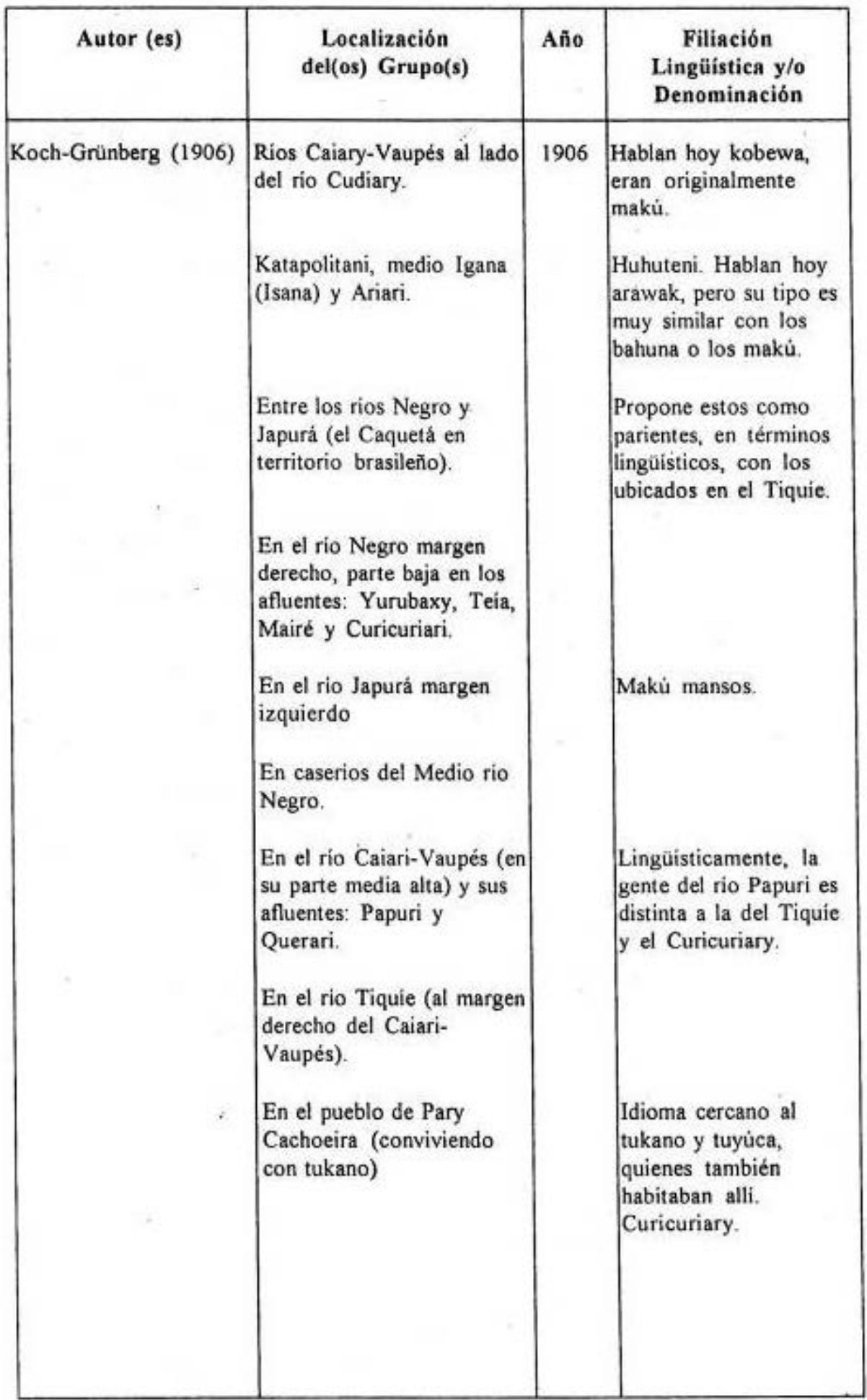




\begin{tabular}{|c|c|c|c|}
\hline Autor (es) & $\begin{array}{c}\text { Localización } \\
\text { del(os) Grupo(s) }\end{array}$ & Año & $\begin{array}{l}\text { Filiación } \\
\text { Lingüistica y/o } \\
\text { Denominación }\end{array}$ \\
\hline Rivet y Tastevin (1920) & $\begin{array}{l}\text { I'roponen tres áreas } \\
\text { lingüisticamente } \\
\text { emparentadas, ubicadas } \\
\text { asi: } \\
\text { 1. Entre el rio Curicuriary } \\
\text { y el rio Negro. } \\
\text { 2. El rio Tiquié en el } \\
\text { Vaupés } \\
\text { 3. En el río Igarapé }\end{array}$ & 1920 & $\begin{array}{l}\text { Confrontan la } \\
\text { información de Koch- } \\
\text { Grünberg (1906) y } \\
\text { retomando su } \\
\text { clasificación lingüistica } \\
\text { proponen la familia } \\
\text { lingüistica makú- } \\
\text { puinave y plantean que } \\
\text { todas las lenguas de } \\
\text { estos grupos son } \\
\text { dialectos de una misma } \\
\text { lengua original. }\end{array}$ \\
\hline Tastevin (1923) & $\begin{array}{l}\text { Entre el medio rio Japurá } \\
\text { y el bajo rio Negro. } \\
\text { Entre el rio Jurubaxy, las } \\
\text { cabeceras del caño Alegria } \\
\text {-afluentes del rio Negro- y } \\
\text { las cabeceras del caño } \\
\text { Cumapi -tributario del rio } \\
\text { Japurá. }\end{array}$ & 1923 & $\begin{array}{l}\text { Guariba, makús bravos } \\
\text { o makús del oeste. } \\
\text { Los makú del Jurubaxi } \\
\text { se refieren a los } \\
\text { Guariba como nadöb y } \\
\text { se autodenominan } \\
\text { Nadöpa para } \\
\text { diferenciarse, eston son } \\
\text { conocidos como makús } \\
\text { mansos y según el } \\
\text { propio autor esta } \\
\text { diferenciación artificial } \\
\text { se refiere al tipo de } \\
\text { relación con los } \\
\text { blancos. }\end{array}$ \\
\hline Nimuendajú (1927) & $\begin{array}{l}\text { Entre los ríos Japurá (parte } \\
\text { media), Negro y } \\
\text { Curicuriary. }\end{array}$ & 1927 & $\begin{array}{l}\text { Distingue los makús } \\
\text { bravos, del lado } \\
\text { brasileño, de los xiriana } \\
\text { y waicas, del alto río } \\
\text { Negro. }\end{array}$ \\
\hline $\begin{array}{l}\text { Marqués de Wavrin } \\
\text { (citado en Pabón 1979) }\end{array}$ & $\begin{array}{l}\text { En la orilla izquierda del } \\
\text { alto rio Negro. } \\
\text { Entre los rios Inirida y } \\
\text { Guaviare. }\end{array}$ & 1948 & $\begin{array}{l}\text { Por la ubicación se } \\
\text { puede deducir que se } \\
\text { trata de los ñ̈kak. }\end{array}$ \\
\hline
\end{tabular}




\begin{tabular}{|c|c|c|c|}
\hline Autor (es) & $\begin{array}{c}\text { Localización } \\
\text { del(os) Grupo(s) }\end{array}$ & Año & $\begin{array}{l}\text { Filiación } \\
\text { Lingïistica y/o } \\
\text { Denominación }\end{array}$ \\
\hline Métraux (1948) & $\begin{array}{l}\text { Plantea tres subdivisiones: } \\
\text { 1. Los ubicados en las } \\
\text { cabeceras del Caño Alegria } \\
\text { y en el Caño Cumapi } \\
\text { (tributarios de los rios } \\
\text { Yapurá y Negro). } \\
\text { Entre el medio Caquetá y } \\
\text { el bajo río Negro, hacia el } \\
\text { rio Curicuariari. } \\
\text { En el alto Caiari-Vaupés, } \\
\text { en el rio Querari y en el rio } \\
\text { Papuri. } \\
\text { 2. Los ubicados entre el rio } \\
\text { Orinoco y el bajo Ventuari. } \\
\text { 3. Ubicados entre los ríos } \\
\text { Uraricuera y el medio } \\
\text { Ariari. }\end{array}$ & 1948 & $\begin{array}{l}\text { Makú mansos. } \\
\text { Guariba. } \\
\text { (makú bravos) } \\
\text { Los yapooa, según } \\
\text { clasificación de } \\
\text { Koch-Grumberg (en } \\
\text { Pineda y Guhl 1945) } \\
\text { Mencionados por } \\
\text { Humboltd. Subgrupo } \\
\text { Piaroa } \\
\text { De lengua aislada, poco } \\
\text { conocidos. Plantea que } \\
\text { se trata de tres tribus no } \\
\text { relacionadas e } \\
\text { independientes } \\
\text { lingüisticamente. }\end{array}$ \\
\hline $\begin{array}{l}\text { Giacone (citado en } \\
\text { Silverwood-Cope } \\
\text { 1990). }\end{array}$ & $\begin{array}{l}\text { En los ríos Papuri y } \\
\text { Tiquie. } \\
\text { En las partes media y alta } \\
\text { del rio Japurá. } \\
\text { Al sur del rio Papuri }\end{array}$ & 1955 & $\begin{array}{l}\text { Pokcé, que es una } \\
\text { denominación dada por } \\
\text { los grupos horticultores } \\
\text { (tukano) que significa } \\
\text { "esclavos", otros dicen } \\
\text { que son "hijos del } \\
\text { jaguar". } \\
\text { Kaboris, nombre dado } \\
\text { por estar cerca del río } \\
\text { Cauabori o Caburi } \\
\text { (afluente del rio } \\
\text { Negro). } \\
\text { Ubde-makú. }\end{array}$ \\
\hline
\end{tabular}




\begin{tabular}{|c|c|c|c|}
\hline Autor (es) & $\begin{array}{c}\text { Localización } \\
\text { del(os) Grupo(s) }\end{array}$ & Año & $\begin{array}{l}\text { Filiación } \\
\text { Lingüística y/o } \\
\text { Denominación }\end{array}$ \\
\hline $\begin{array}{l}\text { Spruce (citado en } \\
\text { Biocca 1965). }\end{array}$ & Río Isana. & 1953 & \\
\hline Schultz (1959) & $\begin{array}{l}\text { En la margen izquierda del río } \\
\text { Japurá, con distintos grados de } \\
\text { aculturación, los menos } \\
\text { aculturados se encuentran } \\
\text { cerca al rio Parana Boá-Boá. } \\
\text { En la región alta del Paraná } \\
\text { Boá-Boá y en las márgenes del } \\
\text { río Uneiuxi (afluente del río } \\
\text { Negro). }\end{array}$ & 1959 & $\begin{array}{l}\text { Los brasileños los } \\
\text { denominan Kaboris. }\end{array}$ \\
\hline Biocca (1965) & $\begin{array}{l}\text { Al norte del rio Caquetá } \\
\text { (Japurá), en el rio Teyá. } \\
\text { Rios Tiquié, Papuri, Querari y } \\
\text { Curicuriari. } \\
\text { Rio Urubaxi. } \\
\text { Orilla derecha del rio Tiquié } \\
\text { (zona de Pary Cachoeira) y } \\
\text { junto a la orilla derecha del rio } \\
\text { Vaupés (zona de Jauareté). }\end{array}$ & 1965 & $\begin{array}{l}\text { Makús bravos o } \\
\text { Guariba (posiblemente } \\
\text { grupos Yanoáma) } \\
\text { Los Makú del Papuri y } \\
\text { Querari, cercanos por } \\
\text { lengua se diferencian } \\
\text { por léxico de los del } \\
\text { Tiquíe y aún más de los } \\
\text { del Curicuriari. } \\
\text { Nadoobo } \\
\text { Makú de Jauareté. } \\
\text { Denominados por los } \\
\text { tukanos, poxsea, que } \\
\text { significa "esclavos". }\end{array}$ \\
\hline Ortiz, S.E. (1965) & $\begin{array}{l}\text { Divide la familia lingüistica en } \\
\text { dos: } \\
\text { 1) Lengua del norte: } \\
\text { Rio Inírida. } \\
\text { 2) Lengua del sur: } \\
\text { Rio Curicuriari } \\
\text { Rio Ducupixi-Igarapé } \\
\text { Rio Tiquié } \\
\text { Rio Yapú-Igarapé } \\
\text { Rio Querari } \\
\text { Rio Papury } \\
\text { Rio Marahna } \\
\text { Rio Jurubaxy }\end{array}$ & 1965 & $\begin{array}{l}\text { Puinave (guaypuño, } \\
\text { uaipi, épined, etc.) } \\
\text { Makú } \\
\text { Dóu } \\
\text { Makú } \\
\text { Húbde } \\
\text { Makú } \\
\text { Ubde-Nehern } \\
\text { Makú } \\
\text { Nadobó }\end{array}$ \\
\hline
\end{tabular}




\begin{tabular}{|c|c|c|c|}
\hline Autor (es) & $\begin{array}{c}\text { Localización } \\
\text { del(os) Grupo(s) }\end{array}$ & Año & $\begin{array}{l}\text { Filiación } \\
\text { Lingiiistica } y / 0 \\
\text { Denominación }\end{array}$ \\
\hline Goldman (1968) & Alto Querari. & 1963 & Makú \\
\hline $\begin{array}{l}\text { Reichel-Dolmatoff } \\
\text { (1967) }\end{array}$ & $\begin{array}{l}\text { Entre el rio Guaviare y las } \\
\text { cabeceras del rio Inirida. } \\
\text { En el rio Papuri. } \\
\text { En el Caño Abiyu. } \\
\text { En el rio Makú-Paraná. }\end{array}$ & 1967 & Makú \\
\hline Munzel (1969) & $\begin{array}{l}\text { Alto Uneiuxi, afluente } \\
\text { directo de medio rio } \\
\text { Negro. }\end{array}$ & 1969 & $\begin{array}{l}\text { Kabori, en su lengua } \\
\text { "hombre", es una } \\
\text { autodenominación. }\end{array}$ \\
\hline Trupp (1972) & $\begin{array}{l}\text { Sobre el rio Apaporis, } \\
\text { cerca al Brasil y en los rios } \\
\text { Jotabeja y Uga. }\end{array}$ & 1972 & $\begin{array}{l}\text { Posiblemente grupos } \\
\text { juhup. }\end{array}$ \\
\hline $\begin{array}{l}\text { Silverwood-Cope } \\
(1990)\end{array}$ & $\begin{array}{l}\text { En las zonas interfluviales } \\
\text { de la región del Vaupés, } \\
\text { entre el rio Negro y el rio } \\
\text { Yapura; retoma la } \\
\text { clasificación de Métraux } \\
\text { (1948). Subdivididos asi: } \\
\text { Al sur del Papurí y alto rio } \\
\text { Tiquie. } \\
\text { Cabeceras de los } \\
\text { tributarios al sur del río } \\
\text { Tiquie. } \\
\text { En el alto Vaupés } \\
\text { colombiano (en los rios } \\
\text { Papuri, Querari y Macu- } \\
\text { Paraná). } \\
\text { Tributarios al norte del rio } \\
\text { Japurá y los tributarios } \\
\text { occidentales del río Negro. }\end{array}$ & 1972 & $\begin{array}{l}\text { Ubde makú. } \\
\text { Yohop makú, } \\
\text { inteligible con el ubde. } \\
\text { Bara-makú (lengua } \\
\text { independiente). } \\
\text { Conocidos como makú } \\
\text { guariba, nadob y } \\
\text { kabori. }\end{array}$ \\
\hline Cathcart $(1973,1979)$ & Rios Papuri y Vaupès. & 1973 & $\begin{array}{l}\text { Cacua: makú de cubeo, } \\
\text { guanano y desano. } \\
\text { Jupdá: makú de tukano. }\end{array}$ \\
\hline
\end{tabular}




\begin{tabular}{|c|c|c|c|}
\hline Autor (es) & $\begin{array}{c}\text { Localización } \\
\text { del(os) Grupo(s) }\end{array}$ & Año & $\begin{array}{c}\text { Filiación } \\
\text { Lingüistica y/o } \\
\text { Denominación }\end{array}$ \\
\hline Reid (1979) & $\begin{array}{l}\text { Al sur de los tributarios } \\
\text { surestes del Tiquie. } \\
\text { Al sureste de los yuhup, } \\
\text { hay un grupo que vive en } \\
\text { las cabeceras del rio } \\
\text { Curicuriari. } \\
\text { Al sureste del rio Téa y } \\
\text { sus principales afluentes, } \\
\text { el Uneiuxi, es conocido } \\
\text { como habitado por makús. } \\
\text { Según el ILV los makús } \\
\text { del Téa, Uneiuxi y el } \\
\text { Parana Boà-Boá, } \\
\text { tributarios al norte del } \\
\text { Japurá, todos hablan } \\
\text { dialectos de la misma } \\
\text { lengua. } \\
\text { Entre el suroeste del rio } \\
\text { Apaporis y el este del rio } \\
\text { Negro todos son miembros } \\
\text { de la misma familia } \\
\text { lingüistica. }\end{array}$ & 1977 & $\begin{array}{l}\text { Bara-makú. } \\
\text { hupdu } \\
\text { Se señalan como hostiles } \\
\text { según otros contactos con no } \\
\text { indios y, virtualmente, no se } \\
\text { conoce nada de ellos (Se } \\
\text { refieren a los ñ̈kak). } \\
\text { Que se designan asi mismos } \\
\text { yuhup. Hablan un dialecto } \\
\text { muy similar al de los hupd. } \\
\text { yuhup. } \\
\text { Se } \\
\text { Se autodenominan nadöb. } \\
\text { Esta lengua es ininteligible } \\
\text { con el hupdu y el bara-makú, } \\
\text { pero la entonación y la } \\
\text { estructura tonal de la lengua } \\
\text { son extremadamente similares } \\
\text { a las dos primeras. } \\
\text { Tentativamente, concluye que } \\
\text { los makú que viven en el área } \\
\text { encerrada por los ríos Vaupés } \\
\text { al norte, el Japurá y los } \\
\text { afluentes, Apaporis al suroeste } \\
\text { y el Rio Negro al este son } \\
\text { todos miembros de la misma } \\
\text { familia lingüistica. } \\
\text { Hasta la fecha, tres lenguas } \\
\text { ininteligibles han sido } \\
\text { reportadas, la unidad yuhup- } \\
\text { hupdu, bara-makú y nadob; } \\
\text { cada una contiene dialectos } \\
\text { diferentes y se puede presu- } \\
\text { poner que dos o más lenguas } \\
\text { puedan existir (Reid 1979). }\end{array}$ \\
\hline
\end{tabular}




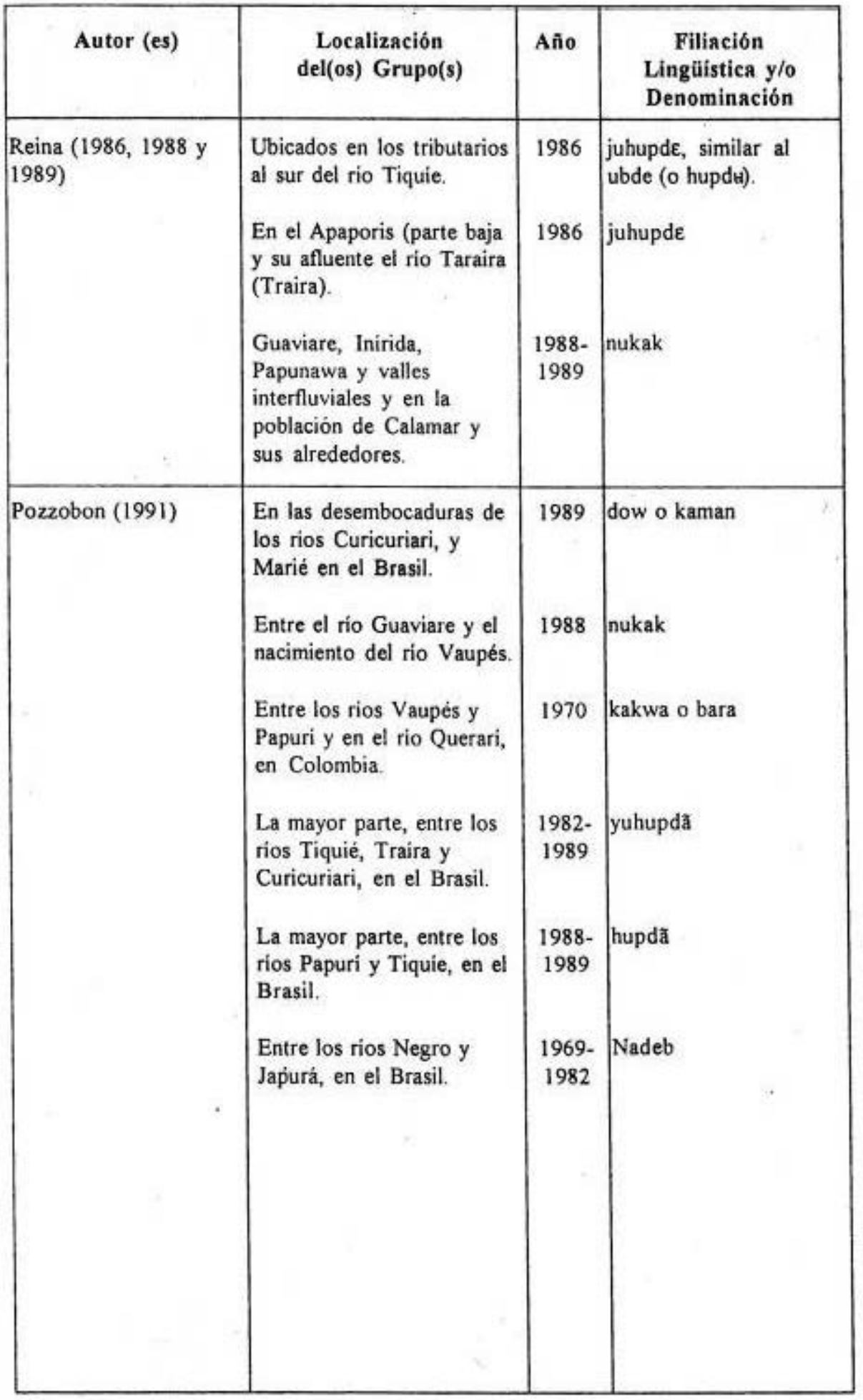




\begin{tabular}{|c|c|c|c|}
\hline Autor (es) & $\begin{array}{c}\text { Localización } \\
\text { del(os) Grupo(s) }\end{array}$ & Año & $\begin{array}{c}\text { Filiación } \\
\text { Lingufistica } \\
\text { y/o } \\
\text { Denominación }\end{array}$ \\
\hline Mondragón (1991) & $\begin{array}{l}\text { "...en las selvas al sur de la Sabana de la } \\
\text { Fuga y al norte y este del caño caparroal } \\
\text { (afluente del rio Inirida) y entre el rio } \\
\text { Guaviare y el río Inirida, desde Charras } \\
\text { hasta el limite Guania-Guaviare y además } \\
\text { al este del caño Caparroal, en las } \\
\text { cabeceras de los caños Wiña, Chucutu y } \\
\text { Mosquito (Guainia). Igualmente al sur } \\
\text { del río Inirida: entre la inesa de la lindosa } \\
\text { y los nacimientós del Inirida; al sur del } \\
\text { lago Esterilla y entre los cerros Santa } \\
\text { Ana, Macú, Mayano y Paloma, la laguna } \\
\text { Macú y los caños Paloma y Barrigudo..." } \\
\text { (p. 3-4). También menciona la posibilidad } \\
\text { de encontrar, en el pasado o actualmente, } \\
\text { Nukak o "Macús" al occidente de } \\
\text { Calamar, al oriente del rio Itilla y de las } \\
\text { cabeceras de los caños tigrera, Los Perros } \\
\text { y Los Cachicamos. Por otra parte entre el } \\
\text { rio Inirida y el Papunaua, sin descartar su } \\
\text { presencia en el sector oriental en } \\
\text { territorios vecinos a los de los puinaves. }\end{array}$ & 1991 & nukak \\
\hline Torres (1991) & $\begin{array}{l}\text { Al este de Caño Grande y el oeste del } \\
\text { Caño Caparroal y entre el río Guaviare y } \\
\text { el Inírida y "es probable que existan otros } \\
\text { grupos por las cabeceras del caño Pupuña } \\
\text { y el Kinikiari (afluentes del Inírida) y el } \\
\text { río Papunaua; y en los interfluvios de las } \\
\text { cabeceras del Inirida, del Unilla y el ltilla } \\
\text { (afluentes que conforman el Vaupés). Así } \\
\text { como en los interfluvios del Ajajú y sus } \\
\text { afluentes (rí Teleya y Caño Macuje), y a } \\
\text { los alrededores de los raudales y sierra del } \\
\text { Chibirequete y de la desembocadura del } \\
\text { Rio Tunia (o Macayá) sobre el rio } \\
\text { Apaporis" (p. 36-37). }\end{array}$ & 1991 & nukak \\
\hline $\begin{array}{l}\text { Politis y Rodriguez } \\
\text { (1994) }\end{array}$ & $\begin{array}{l}\text { "Los distintos trabajos realizados } \\
\text { coinciden en que el territorio actual que } \\
\text { ocupan los Nukak se encuentra entre los } \\
\text { ríos Guaviare e Inirida y entre la Trocha } \\
\text { Central (la que une San José con Calamar) } \\
\text { y Caño Caparroal o Caño Una" (p. 175) }\end{array}$ & 1994 & nukak \\
\hline
\end{tabular}




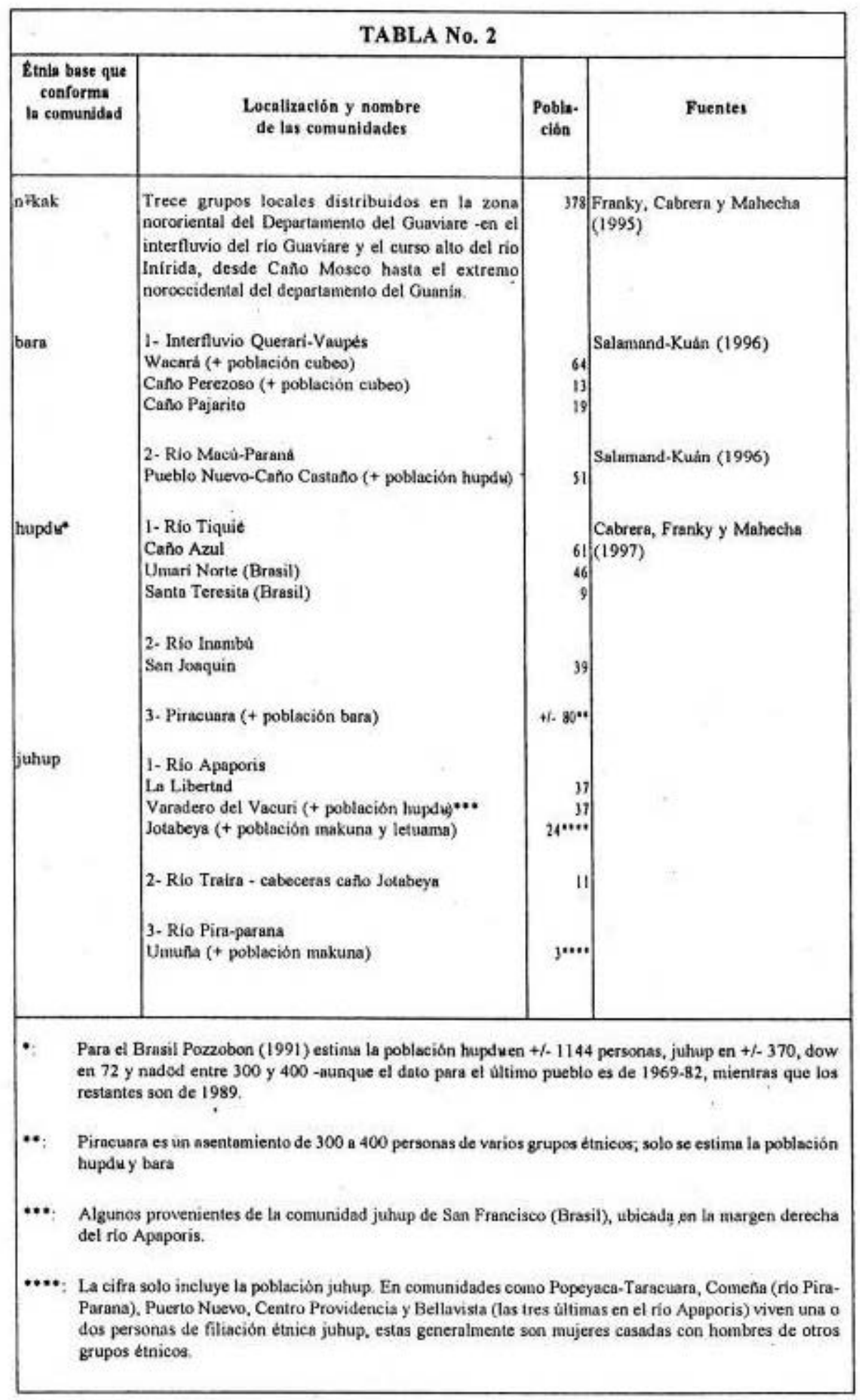




\begin{tabular}{|c|c|c|}
\hline \multicolumn{3}{|c|}{$\begin{array}{c}\text { TABLA No. } 3 \\
\text { ALGUNAS DENOMINACIONES }\end{array}$} \\
\hline $\begin{array}{l}\text { Grupo que da la } \\
\text { denominación } \\
\text { o área en que } \\
\text { se emplea }\end{array}$ & Denominación & Significado \\
\hline $\begin{array}{l}\text { Medio Japurá y bajo medio } \\
\text { rio Negro. }\end{array}$ & $\begin{array}{l}\text { "Makú bravos". } \\
\text { "Makú mansos". }\end{array}$ & $\begin{array}{l}\text { Hostiles a los caucheros. } \\
\text { Más aculturados". }\end{array}$ \\
\hline $\begin{array}{l}\text { Otros grupos de la zona del } \\
\text { medio Japurá y bajo medio } \\
\text { Negro. }\end{array}$ & Guariba & $\begin{array}{l}\text { Apelativo tomado de una } \\
\text { posible traducción de "mico } \\
\text { aullador". }\end{array}$ \\
\hline Rios Querari y Papuri. & Yapooa. & \\
\hline Grupos Tukanos. & $\begin{array}{l}\text { Pokce o poxsèa. } \\
\text { "Hijos del Jaguar" } \\
\text { Tucano-poyá. }\end{array}$ & "Esclavos". \\
\hline Barasana y Taiwano & Josa. & "Sirvientes". \\
\hline Curripaco & $\begin{array}{l}\text { Mãkunaikãisa. } \\
\text { Mãkunai. }\end{array}$ & $\begin{array}{l}\text { "Verdaderos maku". } \\
\text { Seres que no pertenecen } \\
\text { verdaderamente al género } \\
\text { humano, llamado "inaiki". }\end{array}$ \\
\hline Tariana & Pavára-poyá & "Podrido, dañado" \\
\hline Cubeo. & $\begin{array}{l}\text { Borowa. } \\
\text { Mariapwanwa }\end{array}$ & "Gente que se arrastra." \\
\hline Entre el Negro y el Japura. & Kaboris. & $\begin{array}{l}\text { Tomado de un afluente del río } \\
\text { Negro. }\end{array}$ \\
\hline Desana. & Nixi-maxsa & $\begin{array}{l}\text { "Desana dañado", que no son del } \\
\text { todo gente. "La palabra poyari ex- } \\
\text { presa un concepto de invalidez, de } \\
\text { algo incompleto o anormal" (Rei- } \\
\text { chel-Dolmatoff 1986: 44). } \\
\text { Gente que pide, dependientes. }\end{array}$ \\
\hline
\end{tabular}




\section{BIBLIOGRAFÍA}

ARVELLO-JIMÉNEZ, Nelly

1992 Relaciones Politicas en una Sociedad Tribal. Quito. Abyayala y MLAL. Colección 500 años. No. 51 .

ARVELLO-JIMÉNEZ, Nelly, F. Morales y Horacio Biord

1989 Repensando la historia del Orinoco. Revista de Antropología.

Vol V, Nos. 1-2: 154-173.

BIOCCA, Ettore

1965 Viaggi tra gli indi Alto Negro-Alto Orinoco: Apunti di un biologo, Volumen I:Roma: Consigio Nazionale Delle Ricerche.

BUCHILLET, Dominique

S.f. Populaçoes indigenas do Alto rio Negro. (Inédito).

BRUZZI ALVES DA SILVA, Aicionilio

1962 A civilizaçao indigena do Uaupés. São Paulo.Serie Do Centro de Pesguisas de lavreté (Missao Saleciana do Río Negro. Amazonas-Brasil).

CABRERA, Gabriel, Carlos Eduardo Franky y Dany Mahecha 1994 Aportes a la etnografia de los n₹kak y su lengua - aspectos sobre fonologia segmental, Bogotá. Tesis (Antropólogo). Universidad Nacional de Colombia. Departamento de Antropologia. (Inédito).

1997 Del monte a la chagra, de la cerbatana a los anzuelos: Una aproximación a los yujup del río Apaporis. Bogotá. Fundación Gaia Amazonas. (Inédito).

CATHCART, Marilyn

1973 Cacua. En: Aspectos de la cultura material de grupos étnicos de Colombia, Tomo I: 101-123. Lomalinda. Townsend. 
1979 Fonología del Cacua. En: Sistemas fonológicos colombianos, Vol IV: 9-45, Lomalinda.Townsend.

CAUDMONT, Jean

1954 Fonología del Puinave. Revista Colombiana de Antropología. Vol'II, No. 2: 267-276. Bogotá.

CAVELIER, Inés, Camilo Rodriguez, Luisa Fernanda Herrera, Gaspar Morcote y Santiago Mora

1995 No sólo de caza vive el hombre. Ocupación del bosque amazónico, Holoceno Temprano. En: Ambito y ocupaciones tempranas de la América Tropical: 27-44. Inés Cavelier y Santiago Mora (Eds.). Bogotá. Fundación Erigaie e Instituto Colombiano de Antropología.

CIVRIEUX, Marc de

1992 Watunna: Unciclo de creación en el Orinoco. Caracas: Monte Avila.

COPPENS, Walter

1975 Contribución al estudio de las actividades de subsistencia de los Hotis del río Kaima. Boletín Indigenista Venezolano, Vol XVI, Nueva Época: 65-78.

CORREA, François

1983-1984 Elementos de identidad y organización social entre las comunidades indigenas de la Región del Vaupés. Revista Maguaré, Vol II, No. 2: 97-123.

1987

Makú. En: Introducción a la Colombia Amerindia: 123-133. François Correa (Ed.). Bogotá. Instituto Colombiano de Antropologia-Colcultura.

DOMINGUEZ, Camilo y Augusto Gómez

1994 Nación y étnias. Los conflictos territoriales en la Amazonia 1750-1933. Bogotá. Coama - Puerto Rastrojo, Disloque. 
FRANKY, Carlos Eduardo, Dany Mahecha y Gabriel Cabrera

1994 Modos de vida en la amazonia: la construcción del espacio entre los n $\%$ kak (ponencia presentada al VII Congreso de Antropologia en Colombia. Medellin 15-18 junio. (Inédita).

FRANKY, Carlos Eduardo, Gabriel Cabrera y Dany Mahecha

1995 Demografia y movilidad socio-espacial de los nukak. Bogotá.Coama, Earth Love Fund, Danida, Unión Europea y Fundación Gaia - Amazonas.

FRIEDEMANN, Nina S. de y Jaime Arocha

1985 Herederos del Jaguary la anaconda. Bogotá. Carlos Valencia Editores.

GIRÓN, Mario

1995 Morfología de la palabra y la predicación verbal en puinave. Bogotá. Tesis de Magíster (etnolingūista). Centro Colombiano de Estudios en Lenguas Aborigenes - Universidad de los Andes. (Inédita).

GOLDMAN, Irving

1968 Los Cubeo: Indios del Noroeste del Amazonas. México. Instituto Indigenista Americano.

GUMILLA, José

1963 El Orinoco ilustrado, y defendido, historia natural, civil y geographica de este gran rio y de sus caudalosas vertientes. Caracas. Biblioteca Nacional de la Historia.

GÓMEZ, Elsa

1986 Puesto que hablamos distinto, ¿quiere Ud. casarse conmigo? Revista Glotta,. Vol I, No. 3: 18-22. Bogotá

GÓMEZ, Augusto, Ana Lesmes y Claudia Rocha 1995 Caucherias y conflicto colombo-peruano. Bogotá. Coama - Unión Europea y Disloque.

HUGH-JONES, Stephen

1979 The palm and the pleiades. Initiation and Cosmology in Northwest Amazonia. Cambridge. Canbridge University Press. 
1981 Historia del Vaupés. Revista Maguaré, Vol I, No. 1: 29-51. Bogotá.

IRIBERTEGUI, Ramón

1987 Amazonas: El hombre yel caucho. Puerto Ayacucho. Vicariato Apostólico de Puerto de Ayacucho. Monografia No. 4.

JACKSON, Jean

1983 The Fish People. New York. Cambridge University Press.

JOURNET, Nicolas

1988 Les jardins de peix. París. Ecole des Hautes Etudes en Sciences Sociales.

KOCH-GRŨNBERG, Theodor

1906 Die Makú. Antropos. Vol I: 877-906.

LANDABURU, Jon

1990 Estudio Preliminar para el Atlas Etnolingüístico de Colombia. Clasificación de las Lenguas Indigenas de Colombia. C.N.R.S. y Universidad de los Andes. (Inédito).

LATHRAP, Donald

1968 The "hunting" economies of the tropical forest zone of South America: An attempt at historical perspective. En: Man the Hunter: 23-29. Lee and I. Devore, (eds) Chicago. Aldine Publishing Company.

LLANOS, Héctor y Roberto Pineda Camacho

1982 Etnohistoria del Gran Caquetá, Siglos XVI-XIX. Bogotá. Fundación de Investigaciones Arqueológicas Nacionales.

MAHECHA, Dany, Gabriel Cabrera y Carlos Eduardo Franky

En prensa Algunos aspectos fonético-fonológicos del idioma nukak [n+kak]. En: Atlas Etnolingüístico de Colombia. Bogotá. Instituto Caro y Cuervo. 
MATALLANA, Carla y Jon Schackt

1991 Los Jurumi: Una historia oral de una tribu del río Miriti-paraná de la cuenca amazónica. En: Etnohistoria del Amazonas, 460. Congreso de Americanistas Amsterdam: 153-182. Quito: AbyaYala y MLAL. Colección 500 afios, No.36.

MATTEI-MULLER, Marie Claude, Paul Henley y Howard Reid

S.f. Afinidades entre Hodi de Venezuela y grupos makú de Brasil y Colombia. ¿Un descubrimiento lingüístico?. (Datos preliminares). (Inédito).

MEIRA, Marcio

1991 Baniwa, Baré, Warekena, Maku, Tukano ...: os povos indigenas do "baixo rio Negro" querem ser reconhecidos. En: Povos Indigenas no Brasil 1987/88/89/90: 135-140. São Paulo. CEDl.

METRAUX, Alfred

1948 The hunting and gathering tribes of the Negro basin. En: HandBook of South American Indians, Vol. III: 861-867. Julian Steward.(ed) Washington, D.C. Smithsonian Institution, Bureau of American Ethnology.

MILTON, Katherine

1984 Protein and carbohydrate resources of the Maku indians of Northestern Amazonia. American Anthropologist, Vol 86: 727.

MINISTERIO DEL INTERIOR - DIRECCIÓN GENERAL DE ASUNTOS INDIGENAS

1995 Programa de apoyo y fortalecimiento étnico de los pueblos indigenas de Colombia 1995-1998. Bogotá: Sección de Publicaciones y Audivisuales del Ministerio del Interior. Serie Documentos "Pueblos Indigenas en la Nación Diversa". No. 1.

MIRES, Fernando

1992 El discurso de la indianidad. Lacuestión indigena en América Latina. Quito. Abya-Yala y MLAL. Colección 500 años, No. 53. 
MOREY, Robert y Nancy Morey

1975 Relaciones comerciales en el pasado en los llanos de Colombia y Venezuela: 533-562. Caracas. Universidad Católica Andrés Bello. Instituto de Investigaciones Históricas.

MONDRAGÓN, Héctor

1991 Estudio para el establecimiento de un programa de defensa de la comunidad indigena Nukak. Informe final. Bogotá. Plan Nacional de Rehabilitación. (Inédito)

MOORE, Barbara

1976 Algunos aspectos del discurso en Jupda Macú. En: Estudios en Cacua, Jupda y Sáliba: 83-106. Lomalinda: Townsend. Serie Sintáctica No. 3.

MUNZEL, Mark

1969 Notas preliminares sobre os Kabori (Makú entre o río Negro e o Japurá). Revista de Antropologia,Vol XVII-XX, primera parte: $137-181$.

NIMUENDAJU, Curt

1950 Reconocimento dos rios Içána, Ayari e Uaupés: Relatório apresentado ao Serviço de Proteção aos Indios do Amazonas e Acre, 1927. Journal de la Societé des Americanistes, Tomo V: 125-182.

ORTIZ, Sergio Elias

1965 Familias linguisticas de Colombia. En: Prehistoria, Historia Extensa de Colombia, Tomo 3, Vol I: 28-165. Bogotá. Lerner.

ORTIZ, Francisco

1986 Mitologia y organización social en el oriente de Colombia. Revista Maguaré, Vol. III, No, 3: 9-20. Bogotá.

OSPINA, Ana María

1995

Morfología del verbo en la lengua macú-yujup. Bogotá. Tesis de Magister (etnolingüista). Centro Colombiano de Estudios en Lenguas Aborígenes -Universidad de los Andes. (Inédita). 
PABÓN DE TRUJILLO, Magdalena

1979 Relaciones interétnicas, tipos de contacto y sus efectos en la comunidad indigena Puinave del Inírida. Bogotá. Tesis de grado (Antropólogo). Universidad Nacional de Colombia, (Inédito).

PINEDA CAMACHO, Roberto

1985 Historia oral y proceso esclavista en el Caquetá. Bogotá. Fundación de Investigaciones Arqueológicas Nacionales.

PINEDA GIRALDO, Roberto y Ernesto Guhl

1945 Las tribus entre los rios Branco, Orinoco, Negro y Yapura. Resumen y traducción del libro de Fetschitt, Eduard Seler, editado por Walter Lehmonn Stuttgart, Verlog Von Streker un Shocler. 1922: 205-266. Boletín de Arqueología, Vol. I, Tomo I: $171-184$.

POLITIS, Gustavo y Julian Rodriguez

1994 Algunos aspectos de la subsistencia de los Nukak de la Amazonia colombiana. Colombia amazónica, Vol VII, Nos. 1-2: 169-207. Bogotá.

POTTIER, Bernand

1983 Introducción. Las lenguas amerindias, (tercera parte). En: América Latina en sus lenguas indigenas: 183-215. Caracas: Unesco y Monte Ávila.

POZZOBON, Jorge

1991 Os Makú - esquecidos e discriminados. En: Povos Indigenas no Brasil 1987/88/89/90: 141-142. São Paulo: Cedi.

REICHEL-DOLMATOFF, Gerardo

1967 Enquêtes ethnographiques a entreprendre d'urgence (río Vaupés, Colombie). Journal de la Societé des Americanistes. Tomo LVI, No. 2: 323-332.

1986 Desana. 2a Ed. Bogotá. Procultura. 
REICHEL DUSSÁN, Elizabeth

1987 Etnografia de los grupos indigenas contemporáneos. En: Colombia Amazónica: 235-274. la Ed. Bogotá. Universidad Nacional de Colombia-FEN.

REID, Howard

1979 Some aspects of movement, growth and change among the hupdu maku indians of Brazil. Tesis (Ph. D.). University of Cambridge. Faculty of Archaeology and Anthropology.

REINA, Leonardo

1986 Análisis Fonológico, Lengua hupde -Makú, Amazonas. Bogotá. Tesis de Magister (etnolingüista). Centro Colombiano de Estudios en Lenguas Aborigenes -Universidad de los Andes. (Inédita).

1987

Algunas notas sobre la denominación étnica del grupo Makú. Conferencia presentada en el seminario sobre denominación étnica y linguística de grupos indigenas. Bogotá. Instituto Caro y Cuervo. (Inédito)

1988 Informe de comisión entre la comunidad indigena Nukak, corregimiento de Calamar, Guaviare. Bogotá: Instituto Colombiano de Antropología. (Inédito).

1990

Actividades relacionadas con los Nukak. RevistaMopa-Mopa, No. $5,17-28$.

RIVET, Paul y Tastevin, Constant

1920 Affinités du Makú et du Puinave, Journal de la Societé des Américanistes, Vol XII. 69-82.

RIVET, Paul, Kok, P. y Tastevin, Constant 1925 Nouvelle contribution al'étude de la langue Makú. International Journal of American Lingüistics, Vol III, No. 2-4: 133-192. 
RIVERO, Juan

$1956 \quad$ Historia de las misiones de los Llanos de Casanare y los rios Orinoco y Meta. Bogotá. Argra. Biblioteca de la Presidencia de la República, No. 23.

SALAMAND-KUÁN, Catherine.

1996 Atención en salud para comunidades indigenas makú del Vaupés colombiano: informe de actividades 1994-1995. Mitú. Servicio Seccional de Salud del Vaupés. (Inédito).

SCHULTZ, Harold

1959 Ligeiras notas sobre os Makú du Paraná Boá-Boá. Revista do Museo Paulista, nova serie, Vol XI: 109-132. São Paulo.

SEARING, Roberto

1980 Heterogeneidad cultural en el noroeste de la hoya amazónica. Antropológicas. No. 2: 105-117.

SILVERWOOD-COPE, Peter

1990 Os maku: Povo caçador do noroeste da amazonia. Brasilia: Editora Universidade de Brasilia.

TASTEVIN, Constant

1923 Les makú du Japurá. Journal de la Societé des Americanistes, Nouvelle Serie. Tome XV. 99-108.

TORRES, William

1991 Nukak. Informe Final. Bogotá. División de Asuntos Indigenas.

1994 Nukák: aspectos etnográficos. Revista Colombiana de Antropología. Vol. XXXI. 195-234. Bogotá.

TOVAR, Antonio y Larrucea de Tovar Consuelo

1984 Otras lenguas del Marañón al Orinoco, con el grupo Tucano. En: Catálogo de las lenguas de América del sur. 154-167. Madrid. Gredos. 
TRIANA, Gloria

1985 Los puinaves del Inirida: Formas de subsistencia y mecanismos de adaptación. Bogotá. Universidad Nacional de Colombia. Instituto de Ciencias Naturales - Museo de Historia Natural. Biblioteca José Jerónimo Triana No. 8.

USECHE, Mariano

1987 El Proceso colonial en el Alto Orinoco-Negro. (Siglos XVI$X V I I I)$. Bogotá. Fundación de Investigaciones Arqueológicas Nacionales.

WALLACE, Alfred R

1992 Una narración de viajes por el Amazonas y el rio Negro.

[1889] Iquitos. IIAP - CETA. Colección Monumenta Amazónica, serie D, No. 2.

WIRPSA, Leslie y Héctor Mondragón

1988 Resettlement of nukak indians, Colombia. Cultural Survival Quarterly, Vol XII, No. 4: 36-40.

ZUCCHI, Alberta

1989 Las migraciones Maipures: diversas lineas de evidencia para la interpretación arqueológica. Revista América Negra: 114-155. Bogotá. 